\title{
DNA methylome analysis identifies epigenetic silencing of FHIT as a determining factor for radiosensitivity in oral cancer: an outcome-predicting and treatment-implicating study
}

\author{
Hon-Yi Lin ${ }^{1,6,8}$, Shih-Kai Hung ${ }^{1,6}$, Moon-Sing Lee ${ }^{1,6}$, Wen-Yen Chiou ${ }^{1,6}$, Tze-Ta Huang \\ 2,6,7, Chih-En Tseng 3,6, Liang-Yu Shih ${ }^{3,6}$, Ru-Inn Lin ${ }^{1,6,8}$, Jora M.J. Lin ${ }^{8,9}$, Yi-Hui Lai ${ }^{8,9}$, \\ Chia-Bin Chang ${ }^{8,9}$, Feng-Chun Hsu ${ }^{1}$, Liang-Cheng Chen ${ }^{1}$, Shiang-Jiun Tsai ${ }^{1}$, Yu- \\ Chieh Su${ }^{4,6}$, Szu-Chi Li, ${ }^{4,6}$, Hung-Chih Lai ${ }^{4,6}$, Wen-Lin Hsu ${ }^{5,6}$, Dai-Wei Liu ${ }^{5,6}$, Chien- \\ Kuo Tai ${ }^{8,9}$, Shu-Fen Wu ${ }^{8,9}$ and Michael W.Y. Chan ${ }^{8,9,10}$ \\ ${ }^{1}$ Department of Radiation Oncology, Buddhist Dalin Tzu Chi General Hospital, Taiwan, ROC \\ 2 Department of Oral and Maxillofacial Surgery, Buddhist Dalin Tzu Chi General Hospital, Taiwan, ROC \\ ${ }^{3}$ Department of Anatomic Pathology, Buddhist Dalin Tzu Chi General Hospital, Taiwan, ROC \\ ${ }^{4}$ Department of Hematology-Oncology, Buddhist Dalin Tzu Chi General Hospital, Taiwan, ROC \\ ${ }^{5}$ Department of Radiation Oncology, Buddhist Tzu Chi General Hospital, Hualien, Taiwan, ROC \\ ${ }^{6}$ School of Medicine, Tzu Chi University, Hualien, Taiwan, ROC \\ ${ }^{7}$ Institute of Oral Medicine, National Cheng Kung University, Tainan, Taiwan, ROC \\ ${ }^{8}$ Institute of Molecular Biology, National Chung Cheng University, Min-Hsiung, Chia-Yi, Taiwan, ROC \\ ${ }^{9}$ Department of Life Science, National Chung Cheng University, Min-Hsiung, Chia-Yi, Taiwan, ROC \\ ${ }^{10}$ Human Epigenomics Center, National Chung Cheng University, Min-Hsiung, Chia-Yi, Taiwan, ROC \\ Correspondence to: Michael W.Y. Chan, email: biowyc@ccu.edu.tw
}

Keywords: Epigenetics, FHIT, oral cancer, radiotherapy, resistance

Received: September 03, $2014 \quad$ Accepted: November 24, $2014 \quad$ Published: November 25, 2014

This is an open-access article distributed under the terms of the Creative Commons Attribution License, which permits unrestricted use, distribution, and reproduction in any medium, provided the original author and source are credited.

\section{ABSTRACT}

Radioresistance is still an emerging problem for radiotherapy of oral cancer. Aberrant epigenetic alterations play an important role in cancer development, yet the role of such alterations in radioresistance of oral cancer is not fully explored. Using a methylation microarray, we identified promoter hypermethylation of FHIT (fragile histidine triad) in radioresistant OML1-R cells, established from hypofractionated irradiation of parental OML1 radiosensitive oral cancer cells. Further analysis confirmed that transcriptional repression of FHIT was due to promoter hypermethylation, $\mathrm{H} 3 \mathrm{~K} 27 \mathrm{me} 3$ and overexpression of methyltransferase $E Z H 2$ in OML1-R cells. Epigenetic interventions or depletion of EZH2 restored FHIT expression. Ectopic expression of FHIT inhibited tumor growth in both in vitro and in vivo models, while also resensitizing radioresistant cancer cells to irradiation, by restoring Chk2 phosphorylation and G2/M arrest. Clinically, promoter hypermethylation of FHIT inversely correlated with its expression and independently predicted both locoregional control and overall survival in $\mathbf{4 0}$ match-paired oral cancer patient samples. Further in vivo therapeutic experiments confirmed that inhibition of DNA methylation significantly resensitized radioresistant oral cancer cell xenograft tumors. These results show that epigenetic silencing of FHIT contributes partially to radioresistance and predicts clinical outcomes in irradiated oral cancer. The radiosensitizing effect of epigenetic interventions warrants further clinical investigation. 


\section{INTRODUCTION}

Radiotherapy is an important modality for the treatment of oral cancer. After radical surgery, postoperative radiotherapy (with or without chemotherapy) is recommended for patients with pathologically adverse features, such as pT3-4, pN1-3, extracapsular nodal extension, and positive surgical margins [1]. However, a major obstacle is the development of radioresistant cancer cells, eventually leading to locoregional recurrences, and the molecular mechanism that underlies radioresistance is not fully understood.

Unlike genetic events, epigenetic modifications do not involve changes of DNA sequences, but do have profound effects on gene promoter activity [2-4]. Two types of epigenetic modifications are crucial in cancers. First, DNA methylation of promoter "CpG islands" of tumor suppressor genes, resulting in their transcriptional repression, is frequently observed in cancers [5-7]. Second, specific post-translational modifications of chromatin proteins, such as EZH2-mediated trimethylation of histone 3 lysine 27 (H3K27me3), are known transcriptional silencing gene "marks" [8-10]. Interestingly, EZH2bound region of the genes marked by H3K27me3 are able to recruit DNA methyltransferases (DNMTs) for DNA methylation, also resulting in epigenetic silencing of tumor suppressor genes [11].

We and others have previously demonstrated that aberrant promoter hypermethylation of tumor suppressor genes is an important cancer-specific event useful for predicting prognosis in several human cancers [12-15]. For example, we have previously identified promoter hypermethylation of $D A P K$ to be predictive of locoregional control in head and neck cancers [16]. However the role of aberrant epigenetic alterations in radioresistance of oral cancer is not fully explored.

In the current study, we established an in vitro model to investigate the role of aberrant epigenetic modifications in the development of oral cancer radioresistance. Using a methylation microarray, we show that promoter hypermethylation of Fragile histidine triad (FHIT) facilitates radioresistance after massive irradiation in oral cancer cells, and that this event has in vitro and in vivo prognostic value for demarcating possible radioresensitization of this deadly disease by epigenetic interventions.

\section{RESULTS}

\section{Differential methylation analysis between OML1-P and OML1-R cells}

To explore the role of epigenetic modifications in the onset of radioresistant oral cancer, we developed a radioresistant oral cancer cell (OML1-R) subline, from parental OML1-P cell, using a hypo-fractionated irradiation protocol (5Gy by 10 fractions; Fig. 1A). A single test fraction of 10-Gy irradiation confirmed the established radioresistance of OML1-R cells, as compared to the parental cells $(P<0.0001$; Fig. 1B, C).

To identify genes differentially methylated in radioresistant cells, OML1-R and the parental cells were compared by methylation analysis using Illumium $27 \mathrm{~K}$ methylation BeadChip microarrays. Of approximately 300 probes found to be significantly hypermethylated in OML1-R cells (Fig. 1D, red spots), and filtering for probes with initial $\beta$ values of $<0.5$ in the parental cells, 180 probes were found significantly hypermethylated (Supplementary Table S2). Subjecting this set of differentially methylated genes to ontology analysis by DAVID [17] revealed several significantly enriched biological processes (Supplementary Table S3).

Aberrant DNA methylation has been previously reported in cellular non-response to ionizing radiation, particularly for genes involved in cell cycle control, DNA repair, and apoptosis [18]. In this regard, genes significantly enriched in the corresponding biological processes (purine nucleoside metabolic process and DNA metabolic process), based on our gene ontology analysis, were further screened. One of the targets, FHIT, a gene that regulates $\mathrm{G} 2 / \mathrm{M}$ checkpoint and apoptosis was then selected for further analysis. FHIT was also selected based on its location in a fragile chromosome site (3p13.2) that would likely be damaged by ionizing irradiation [19].

\section{FHIT is epigenetically silenced in OML1-R cells}

To validate our microarray result, we performed methylated-binding DNA (MBD) capture coupled to real time PCR (MBDcap-PCR), in addition to bisulphite pyrosequencing, of the promoter region of FHIT (Fig. 2A). Both MBDcap-PCR (Fig. 2B) and bisulphite pyrosequcening (Fig. 2C) confirmed higher FHIT promoter methylation in OML1-R than in OML1-P cells. More importantly, FHIT promoter hypermethylation associated with down-regulation of its mRNA and protein (Fig. 2D). These phenomenon may be attributed to an increased expression of DNMT3a, $3 b$ but not DNMT 1 in OML1-R cells (Fig. S2).

We also conducted H3K27me3 ChIP-PCR to examine the histone chromatin status of the promoter region of FHIT in OML1-R and the parental cells. As expected, OML1-R cells possessed higher H3K27me3 levels around the promoter region of the FHIT gene (Fig. $2 \mathrm{E})$. The enrichment of this repressive histone mark may be due to overexpression of the histone methyltransferase, EZH2 in OML-1R cells (Fig. 2F).

EZH2 is a key component of the Polycomb repressive complex 2 (PRC2) and is involved in transcriptional repression [20]. Previous studies 
demonstrated that EZH2-mediated H3K27me3 correlates tightly with DNA methylation [11, 21-22] or at least in a regional-dependent manner [23]. However, contradictory evidences also suggested that $\mathrm{H} 3 \mathrm{~K} 27 \mathrm{me} 3$ and DNA methylation are mutually exclusive [24-25]. To examine the role of EZH2 in the epigenetic silencing of FHIT, we depleted EZH2 in OML1-R cells (Fig 3A). As expected, lentiviral knock-down of EZH2 resulted in a re-expression of FHIT in OML1-R cells (Fig 3B). This re-expression is accompanied by a relaxation of chromatin as demonstrated by about 2-fold increase of $\mathrm{H} 3 \mathrm{~K} 4 \mathrm{me} 3$ and 2-fold decrease of $\mathrm{H} 3 \mathrm{~K} 27 \mathrm{me} 3$ in the promoter region of FHIT (Fig 3C). Importantly, EZH2-depleted cells also showed a $10 \%$-decrease of FHIT promoter methylation as demonstrated by bisulphite pyrosequencing (Fig 3D). These results suggested that promoter methylation of FHIT is partially controlled by EZH2 in the promoter region of FHIT.

A

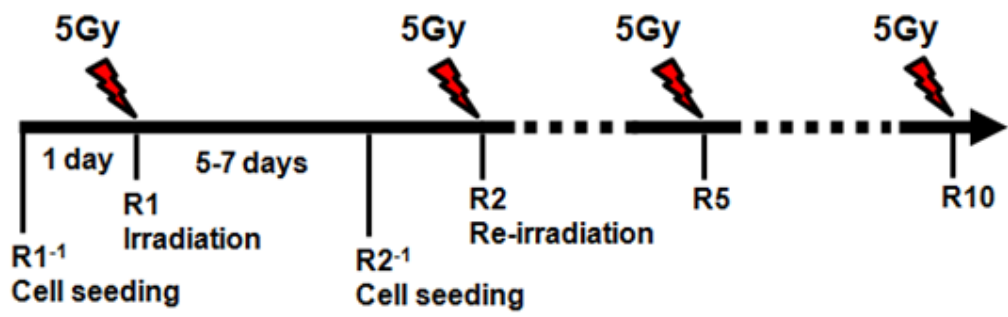

B
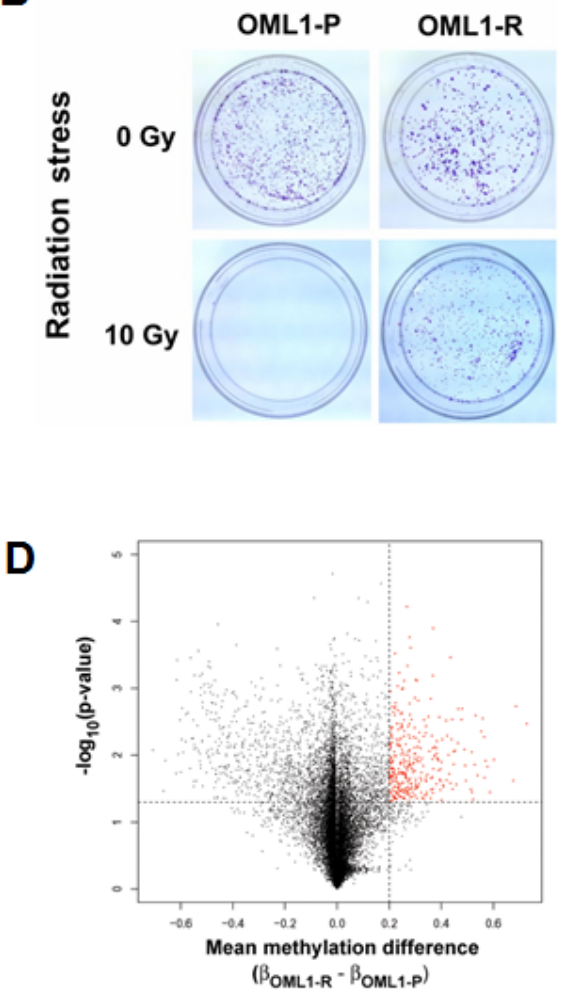

C.

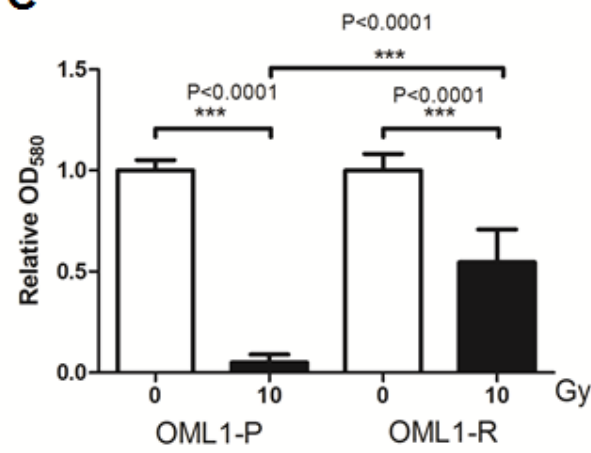

Figure 1: Establishment of a radioresistant oral cancer cell subline and its differential methylation profile. (A) Timeline schema for establishing a radioresistant oral cancer cell subline. One day before irradiation (R1 ${ }^{-1}, \mathrm{R} 2^{-1} \ldots$ etc), cells were seeded onto 10 $\mathrm{cm}$ cell culture plates. On the following day (R1, R2 ...R10), a fraction of 5-Gy irradiation was delivered using a 6-MV linear accelerator. The cells were allowed to recover for 5-7 days before another round of irradiation. This process was repeated for up to 10 fractions (R10) until a total dose of 50 Gy was obtained. The irradiations from R2 to R10 are indicated by dash line. (B) Radiation stress test in parental OML1-P and radioresistant OML1-R cells using a single 10-Gy irradiation. Cells were allowed to recover for several days and then stained with $0.4 \%$ crystal violet (C) Quantitative analysis of the radiation stress test described in B. Stained cells were lysed and measured by a spectrophotometer, and the relative number of cells were expressed as $\mathrm{OD}_{580}$. Data are expressed as means $\pm \mathrm{SD}(\mathrm{n}=3$ ). (D) Volcano plot showing methylation differences and P values of each probe between OML1-R and their parental OML1-P cells. A total of 24,000 gene loci were compared. Of these, 330 probes (red) demonstrated an increased $\beta$ value $\geq 0.2$ and $\mathrm{P}<0.05$, in OML1-R cells. 


\section{Epigenetic drug treatment restores FHIT expression in OML1-R cells}

To further investigate whether epigenetic derepressors might reverse FHIT silencing, we found that treatment of OML1-R cells with a DNMT inhibitor (5-aza-2'-deoxycytidine, 5-Aza) alone, but not an HDAC inhibitor (TSA) alone, could restore FHIT expression (Fig. 4A), while combination 5-Aza/TSA treatment resulted in additive effect of FHIT re-expression. Interestingly, treatment with an EZH2 inhibitor (GSK343), which specifically inhibits H3K27me3 [26], elicited robust reactivation of FHIT. Remarkably, combination treatment of 5-Aza and GSK343 resulted in the highest level of FHIT re-expression (Fig. 4A).

A

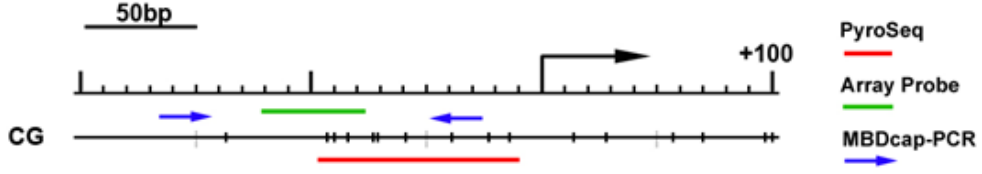

B

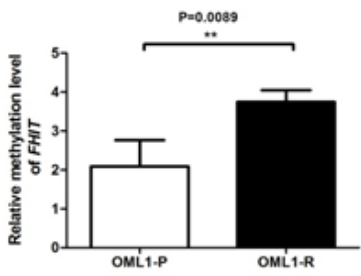

D

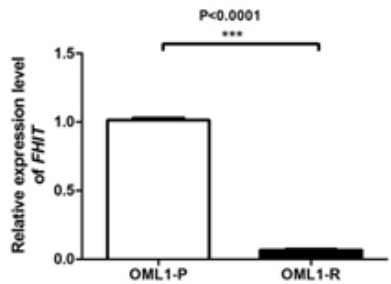

OML1-P OML1-R

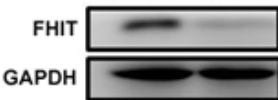

$\mathbf{F}$

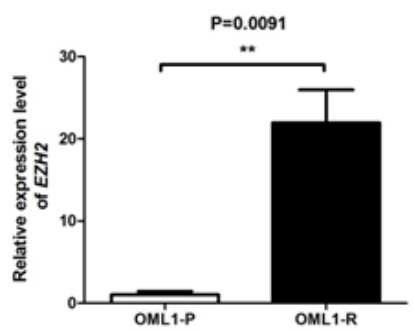

C

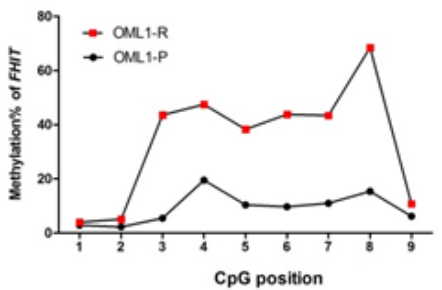

$\mathbf{E}$

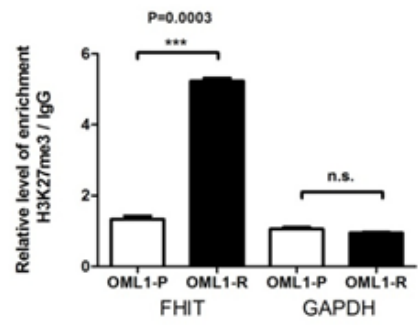

Figure 2: Validation of promoter methylation and FHIT expression in oral cancer cells. (A) Schematic diagram depicting the position of CG sites in the promoter region of FHIT. The red line represents the region subjected to bisulphite pyrosequencing, containing $9 \mathrm{CpG}$ sites. The location of the microarray probe (green), and primers for MBDcap-PCR (blue arrows) are also indicated. The methylation level of FHIT was determined by (B) MBDcap-PCR and (C) bisulphite pyrosequencing. (D) Expression of FHIT in the radio-sensitive vs. -resistant cells was also determined by qRT-PCR (upper panel) and Western blot analysis (lower panel). (E) ChIP assays were performed with antibodies against trimethyl-H3-K27 (H3K27me3) in the promoter regions of FHIT and GAPDH (as control) in OML1-P and OML1-R cells. The relative level of enrichment was determined by real-time PCR and normalized to the Ct value of IgG-pulled-down DNA alone. Higher levels of H3K27me3 were observed in OML1-R cells. (F) Expression of EZH2 in OML1-P and OML1-R was determined by qRTPCR. Data in the histogram are expressed as means $\pm \mathrm{SD}(\mathrm{n}=3)$. 


\section{FHIT is epigenetically silenced in a panel of oral cancer cell lines}

We then explored the correlation between FHIT expression and promoter methylation in a primary human oral keratinocyte $(\mathrm{HOK})$ and four other oral cancer cell lines (OCSL, SCC25, SAS, and SCC4). As expected, similar to OML1-R cells, FHIT expression (Fig. 4B) demonstrated a tight inverse correlation with promoter methylation of FHIT (Fig. 4C) in those cells. Taken together, these results strongly suggest that epigenetic modifications contribute to the process of radioresistance via down-regulation of FHIT in oral cancer cells.

A
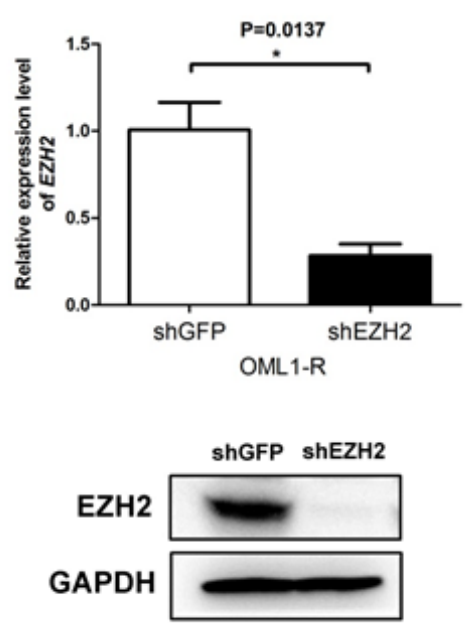

C

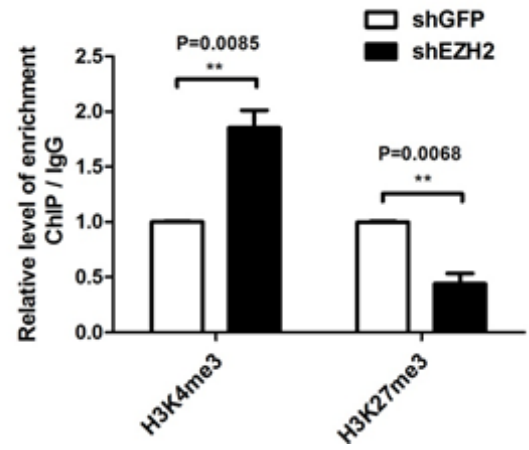

\section{Overexpression of $F H I T$ restores radiosensitivity} in OML1-R cells

Next, we want to investigate the role of FHIT in radiosensitivity. OML1-R cells were transfected with an FHIT-overexpressing cDNA myc-tag plasmid (Fig. 5A). Compared to control cells, OML1-R cells overexpressed with FHIT formed fewer colonies after a single fraction of 10-Gy irradiation, supporting a role for FHIT in radiosensitivity (Fig. 5B, C). Moreover, overexpression of FHIT significantly induced apoptosis in OML1-R cells after irradiation (Fig. 5D and S3). Finally, FHIT overexpression restored phosphorylation of Chk2 (Fig. 5E), expression of $\mathrm{p} 21$ (Fig. S4) and activation of G2/M checkpoint (Fig. 5F) in irradiated OML1-R cells. Taken

B

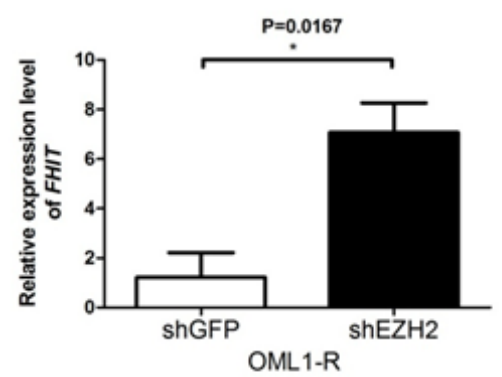

D

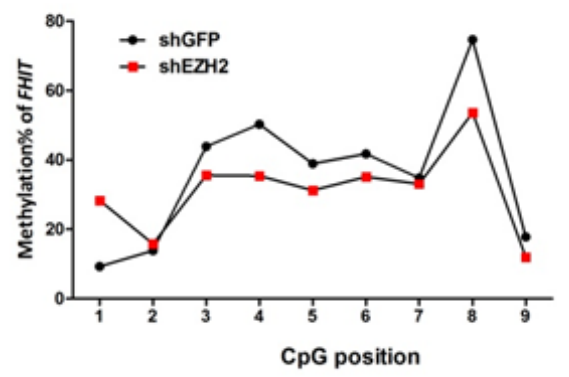

Figure 3: The role of EZH2 in the epigenetic silencing of $\boldsymbol{F H I T}$. OML1-R cells were infected with shRNA against EZH2 or GFP (control). (A) Expression of EZH2 in the infected cells were determined by qRT-PCR (upper panel) and Western blot analysis (lower panel). (B) Expression level of FHIT was determined by qRT-PCR in control and EZH2-depleted OML1-R cells. Histone modifications (H3K4me3 and $\mathrm{H} 3 \mathrm{~K} 27 \mathrm{me} 3$ ) and promoter methylation of FHIT in the control and EZH2-depleted cells were determined by ChIP-qPCR and bisulphite pyrosequencing respectively. Interestingly, depletion of EZH2 reversed histone modifications (C) and reduced promoter methylation (D) of $F H I T$ in EZH2-depleted OML1-R cells. 
Table 1: Patient characteristics according to distance of pathological surgical margin

$\begin{array}{cc}\text { Pathological surgical margin, } n(\%) & \text { Total, } n(\%)\end{array} \quad P$ value

\begin{tabular}{|c|c|c|c|c|}
\hline \multicolumn{5}{|l|}{ Patient } \\
\hline Age* & & & & 0.99 \\
\hline$\leq 50$ years & $8(40.0)$ & $8(40.0)$ & $16(40.0)$ & \\
\hline$>50$ years & $12(60.0)$ & $12(60.0)$ & $24(60.0)$ & \\
\hline Gender* & & & & 0.99 \\
\hline Female & $1(5.0)$ & $1(5.0)$ & $2(5.0)$ & \\
\hline Male & $19(95.0)$ & $19(95.0)$ & $38(95.0)$ & \\
\hline ECOG PS & & & & 0.99 \\
\hline $0-1$ & $17(85.0)$ & $17(85.0)$ & $34(85.0)$ & \\
\hline$\geq 2$ & $3(15.0)$ & $3(15.0)$ & $6(15.0)$ & \\
\hline Betel nut chewing & & & & 0.67 \\
\hline No & $3(15.0)$ & $4(20.0)$ & $7(17.5)$ & \\
\hline Yes & $17(85.0)$ & $16(80.0)$ & $33(82.5)$ & \\
\hline \multicolumn{5}{|l|}{ Tumor } \\
\hline Histology & & & & 0.15 \\
\hline Grade 1-2 & $19(95.0)$ & $16(80.0)$ & $35(87.5)$ & \\
\hline Grade 3-4 & $1(5.0)$ & $4(20.0)$ & $5(12.5)$ & \\
\hline pT status & & & & 0.18 \\
\hline pT1-3 & $16(80.0)$ & $11(55.0)$ & $27(67.5)$ & \\
\hline pT4 & $4(20.0)$ & $9(45.0)$ & $13(32.5)$ & \\
\hline pN status & & & & 0.67 \\
\hline pNo & $16(80.0)$ & $17(85.0)$ & $33(82.5)$ & \\
\hline $\mathrm{pN} 1-2$ & $4(20.0)$ & $3(15.0)$ & $7(17.5)$ & \\
\hline Pathology stage* & & & & 0.99 \\
\hline non-IVA/B & $11(55.0)$ & $11(55.0)$ & $22(55.0)$ & \\
\hline IVA/B & $9(45.0)$ & $9(45.0)$ & $18(45.0)$ & \\
\hline \multicolumn{5}{|l|}{ Treatment } \\
\hline Post-OP therapy & & & & 0.21 \\
\hline RT alone & $12(60.0)$ & $7(35.0)$ & $19(47.5)$ & \\
\hline CCRT & $8(40.0)$ & $13(65.0)$ & $21(52.5)$ & \\
\hline RT Dose & & & & 0.75 \\
\hline$\leq 66 \mathrm{~Gy}$ & $12(60.0)$ & $10(50.0)$ & $22(55.0)$ & \\
\hline$>66 \mathrm{~Gy}$ & $8(40.0)$ & $10(50.0)$ & $18(45.0)$ & \\
\hline Total & $20(100)$ & $20(100)$ & $40(100)$ & \\
\hline
\end{tabular}

Abbreviations: ECOG PS, Eastern Cooperative Oncology Group Performance Status Post-OP, PostOperative; RT, Radiotherapy; CCRT, Chemo-radiotherapy; Gy, Gray.

Note 1: All $P$ values were estimated by using the Fisher's exact test.

Note 2: ECOG performance status was recorded by a radiation oncologist at the time of initial presentation at RT department.

Note 3: Factors that marked with "*” were used for match-paired. 
Table 2: Association between promoter methylation of FHIT and clinical-pathological features in 40 oral cancer patients

\begin{tabular}{|c|c|c|}
\hline & Methylation (\%) & $P$ \\
\hline \multicolumn{3}{|l|}{ Patient } \\
\hline \multicolumn{3}{|l|}{ Age } \\
\hline$\leq 50$ years & $21.36 \pm 21.29^{1}(16 / 40)^{2}$ & \\
\hline$>50$ years & $25.98 \pm 22.67(24 / 40)$ & 0.52 \\
\hline \multicolumn{3}{|l|}{ Gender } \\
\hline Female & $4.76 \pm 3.09(2 / 40)$ & \\
\hline Male & $25.16 \pm 22.17(38 / 40)$ & $<0.001^{3}$ \\
\hline \multicolumn{3}{|l|}{ Smoking } \\
\hline No & $14.61 \pm 14.29(6 / 40)$ & \\
\hline Yes & $25.82 \pm 22.81(34 / 40)$ & 0.16 \\
\hline \multicolumn{3}{|c|}{ Betel nut chewing } \\
\hline No & $12.23 \pm 14.01(7 / 40)$ & \\
\hline Yes & $26.67 \pm 22.78(33 / 40)$ & $0.047^{3}$ \\
\hline \multicolumn{3}{|l|}{ Tumor } \\
\hline \multicolumn{3}{|l|}{ Histology } \\
\hline Grade 1-2 & $23.17 \pm 20.95(35 / 40)$ & \\
\hline Grade 3-4 & $30.91 \pm 30.79(5 / 40)$ & 0.61 \\
\hline \multicolumn{3}{|l|}{ pT status } \\
\hline pT1-3 & $15.83 \pm 12.15(27 / 40)$ & \\
\hline pT4 & $28.13 \pm 22.58(13 / 40)$ & 0.084 \\
\hline \multicolumn{3}{|l|}{$\mathrm{pN}$ status } \\
\hline pN0 & $23.70 \pm 20.95(33 / 40)$ & \\
\hline pN1-2 & $26.58 \pm 24.21(7 / 40)$ & 0.83 \\
\hline \multicolumn{3}{|l|}{ PNI } \\
\hline No & $21.91 \pm 19.97(31 / 40)$ & \\
\hline Yes & $31.79 \pm 28.13(9 / 40)$ & 0.35 \\
\hline \multicolumn{3}{|l|}{ LVSI } \\
\hline No & $12.60 \pm 9.61(33 / 40)$ & \\
\hline Yes & $26.59 \pm 23.25(7 / 40)$ & $0.017^{3}$ \\
\hline
\end{tabular}

together, these results suggest that FHIT may mediate radiosensitivity by inducing apoptosis and activation of a G2/M checkpoint.

\section{Expression of FHIT is associated with radiosensitivity in oral cancer cells}

The above experiments demonstrated that epigenetic silencing of FHIT may contribute to the radioresistance in OML1-R cells, while restoring FHIT expression facilitates radiosensitivity. To avoid the possibility of cell line effects, we investigated the radiosensitivity in another two oral cancer cell lines (SAS, SCC25), both of which endogenously underexpress FHIT (Fig. 4B). Interestingly, both SAS and SCC25 cells demonstrated an intrinsic radioresistance (Fig 6B, D, Control), while ectopic FHIT expression significantly increased the radiosensitivity in these two cells (Fig. 6A-D).

We also performed a reciprocal experiment of knocking down FHIT in OSCL cells, which intrinsically highly express FHIT (Fig. 6E). Consistent with a role in radiosensitivity, FHIT knockdown slightly enhanced OSCL cell radioresistance (Fig. 6F). These results further suggest a role for FHIT in oral cancer radiosensitivity.

\section{Epigenetic silencing of $\boldsymbol{F H I T}$ is correlated with poor clinical outcome in oral cancer patients}

To further examine a clinical role for FHIT in oral cancer progression, we investigated its promoter methylation and expression in 40 match-paired, paraffinembedded oral cancer patient samples (Fig. S1, Table 1 
Table 3: Hazard ratio for locoregional recurrence according to predictive factors

HR (95\% CI); $P$ value

Univariate

Multivariate

Patient factors

Age ( $\leq 50$ vs. $>50$ years)

$2.92(0.71-12.01) ; 0.14$

NA

Gender (female vs. male)

$4.61(0.25-86.58) ; 0.31$

NA

Smoking (no vs. yes)

$0.72(0.08-6.77) ; 0.77$

NA

Betel nut chewing (no vs. yes)

$3.99(0.28-56.86) ; 0.31$

NA

ECOG PS (0-1 vs. $\geq 2)$

$2.34(0.40-13.69) ; 0.62$

NA

\section{Tumor factors}

Histology (G1-2 vs. G3-4)

Depth ( $\leq$ submucosa vs. $\geq$ muscle)

PNI (no vs. yes)

LVSI (no vs. yes)

ECS (no vs. yes)

p-Stage (non-IVA/B vs. IVA/B)

$$
\begin{array}{rr}
1.49(0.58-3.83) ; 0.24 & \text { NA } \\
1.69(0.41-8.02) ; 0.52 & \text { NA } \\
1.98(0.71-5.94) ; 0.28 & \text { NA } \\
1.52(0.51-5.38) ; 0.59 & \text { NA } \\
7.86(<0.01->100) ; 0.96 & \text { NA } \\
7.05(1.14-43.5) ; \mathbf{0 . 0 3 6 *} & 5.25(1.08-25.57) \\
& \\
6.36(1.48-27.33) ; \mathbf{0 . 0 1 1 ^ { * * }} & 4.36(1.22-15.5) ; \\
2.83(0.88-9.31) ; \mathbf{0 . 0 8 6 *} & 3.58(0.48-26.7 \\
3.08(0.67-14.15) ; 0.27 & \text { NA }
\end{array}
$$$$
\text { NA }
$$$$
1.98(0.71-5.94) ; 0.28 \quad \text { NA }
$$$$
\text { NA }
$$$$
5.25(1.08-25.57) ; \mathbf{0 . 0 4 7 *}
$$

\section{Treatment factors}

\author{
Surgical margin (>1 vs. $\leq 1 \mathrm{~mm}$ ) \\ Post-OP therapy (RT vs. CCRT) \\ RT dose ( $\leq 66$ vs. $>66 \mathrm{~Gy})$
}

Gene promoter methylation

FHIT (no vs. yes)
$14.55(1.67->100) ; \mathbf{0 . 0 3 9}$ **

\author{
$4.36(1.22-15.5) ; 0.023^{* *}$ \\ $3.58(0.48-26.7) ; 0.11$
}

NA

Abbreviation: CI, confidence interval; PNI, peri-neural infiltration; LVSI, lymph-vascular space invasion; ECS, extracapsular spreading; ECOG PS, Eastern Cooperation Oncology Group performance status; FHIT, fragile histidine triad; HR, hazard ratio; 95\% CI, 95\% confidence interval; **, $P<0.05 ; *, P<0.10$ but $\geq 0.05$.

Note 1: The first group in all predictive factors was used as the reference group for estimating hazard ratio. For example, ' $\leq 50$ years' was the reference group (value $=1$ ) in the factor of 'Age.'

Note 2: Factors with a univariate $P$ value of $<0.10$ were used for further multivariate analvsis.

and 2). Results from bisulphite pyrosequencing revealed a higher median methylation level in high-staged patients than that of low-staged patients $(P=0.0143$; Fig. 7A). Importantly, patients with a negative staining of FHIT demonstrated a significantly higher promoter methylation of FHIT than that of patients with positive staining of FHIT $(P=0.0395$, Fig. 7B). Moreover, patients with a higher FHIT methylation $(>10 \%, \mathrm{n}=22 / 40)$ showed a lower locoregional control rate than that of patients with lower methylation $(P=0.038$; Fig. 7C). Remarkably, this predicting ability further translated into overall survival $(P$ $=0.024$; Fig. 7D). To exclude the effect of chemotherapy, we also performed a subgroup analysis in patients treated with post-operative radiotherapy alone $(\mathrm{n}=19)$. However, due to the small sample size, we only observed a trend that patients with higher FHIT methylation tend to have a 2-fold lower locoregional control rate than that of patients with lower methylation (survival\%: high vs low methylation, $33.9 \%$ vs $66.7 \%, P=0.0998$ ). Moreover, consistent with methylation results, patients lacking FHIT expression also showed a lower locoregional control rate than that of patients expressing FHIT $(P=0.046$; Fig. 7E, Fig. S5).

Multivariate analysis also confirmed that FHIT promoter hypermethylation was an independent risk factor for predicting poor locoregional control (HR, 11.55; 95\% CI, $1.41-99.9 ; P=0.043$; Table 3 ) and poor overall survival (HR, 3.06; 95\% CI, $1.15-8.14 ; P=0.036$; Table 4). As expected, in addition to FHIT promoter hypermethylation, advanced pathological stage and very 
Table 4: Hazard ratio for overall survival according to predictive factors

HR $(95 \%$ CI $) ; P$ value

Univariate

Multivariate

\section{Patient factors}

Age ( $\leq 50$ vs. $>50$ years)

Gender (female vs. male)

Smoking (no vs. yes)

Betel nut chewing (no vs. yes)

ECOG PS (0-1 vs. $\geq 2)$

\section{Tumor factors}

Histology (G1-2 vs. G3-4)

Depth ( $\leq$ submucosa vs. $\geq$ muscle)

PNI (no vs. yes)

LVSI (no vs. yes)

ECS (no vs. yes)

p-Stage (non-IVA/B vs. IVA/B)

\section{Treatment factors}

Surgical margin (>1 vs. $\leq 1 \mathrm{~mm}$ )

Post-OP therapy (RT vs. CCRT)

RT dose ( $\leq 66$ vs. $>66$ Gy)

Gene promoter methylation

FHIT (no vs. yes)

$$
1.52(0.40-5.73) ; 0.54
$$

$1.18(0.06-25.54) ; 0.91$

$0.99(0.09-11.21) ; 0.99$

$4.61(0.29-70.95) ; 0.27$

$2.86(0.89-9.20) ; 0.083^{*}$

3.17 (0.44-23.09); 0.25

$1.19(0.38-3.83) ; 0.63$

$1.28(0.39-4.20) ; 0.48$

$1.72(0.52-5.84) ; 0.46$

$9.36(<0.01->100) ; 0.92$

10.25 (1.64 - 64.6); 0.009*

$$
\begin{gathered}
5.84(1.58-21.63) ; \mathbf{0 . 0 1 7} * * \\
2.48(0.93-6.61) ; \mathbf{0 . 0 6 1 *} \\
1.98(0.45-8.70) ; 0.58
\end{gathered}
$$

$6.12(1.98-3.09) ; \mathbf{0 . 0 2 8} * *$
NA

NA

NA

NA

$1.93(0.48-71.32) ; 0.56$

NA

NA

NA

NA

NA

$2.91(1.44-5.98) ; 0.020$ *

$2.24(1.27-1.76) ; \mathbf{0 . 0 3 2} *$

$1.83(0.62-5.41) ; 0.38$

NA

Abbreviation: CI, confidence interval; PNI, peri-neural infiltration; LVSI, lymph-vascular space invasion ; ECS, extracapsular spreading; ECOG PS, Eastern Cooperation Oncology Group performance status; FHIT, fragile histidine triad; HR, hazard ratio; $\mathbf{9 5 \%}$ CI, $95 \%$ confidence interval; **, $P<0.05 ; *, P<0.10$ but $\geq 0.05$.

Note 1: The first group in all predictive factors was used as the reference group for estimating hazard ratio. For example, ' $\leq 50$ years' was the reference group (value $=1$ ) in the factor of 'Age.'

Note 2: Factors with a univariate $P$ value of $<0.10$ were used for further multivariate analysis.

close surgical margin were also identified as independent factors for predicting shortened overall survival (Table 4).

We further explored the outcome-predicting role of three independent factors (promoter methylation, stage, and very close surgical margin). Both Kaplan-Meier (Fig. S6) and Cox regression analysis (Table S4) demonstrated that patients with any two of these three factors or all three factors had poorer clinical outcomes than those with only one or no risk factor.

\section{Epigenetic interventions enhance radiosensitivity, in vivo}

Next, we tested the role of FHIT in tumor growth and radiosensitivity in an in vivo xenograft mouse model. Compared to empty vector control, FHIT -overexpressing
OML1-R cells exhibited significantly less tumor growth than mice injected with mock-transfected OML1-R cells (Fig. 8A, B), thus confirming high tumor suppression by FHIT, in vivo.

Since FHIT was epigenetically silenced in OML1-R cells, and radioresistance correlated with aberrant epigenetic changes in vitro, we examined the possibility of in vivo epigenetic interventions to resensitize OML1-R cells to irradiation. Mice were subcutaneously injected with OML1-R cells, followed by treatment of radiotherapy (RT, 4-Gy by 2 fractions), i.p administration of 5-Aza or concurrent 5-Aza and RT. Significant reduction in tumor volumes was observed in mice treated with combined 5-Aza and RT when compared with 5-Aza or RT alone (Fig. 8C, D) demonstrating a synergistic effect and potential treatment direction of combining demethylating 
agents with RT.

\section{DISCUSSION}

In the therapy of oral cancer, after massive irradiation, it is believed that radioresistant cancer cells harbored in the surgical bed are the likely sources of locoregional recurrence [27]. Moreover, post-irradiation epigenetic changes have been suggested to play a significant role in eliciting radioresistance of irradiated cancer cells [18, 28-29]. These phenomena make "epimutations" attractive bio-targets for both predicting clinical outcomes and enhancing treatment efficacy. However, the role of epigenetic changes in radioresistant

\section{A}

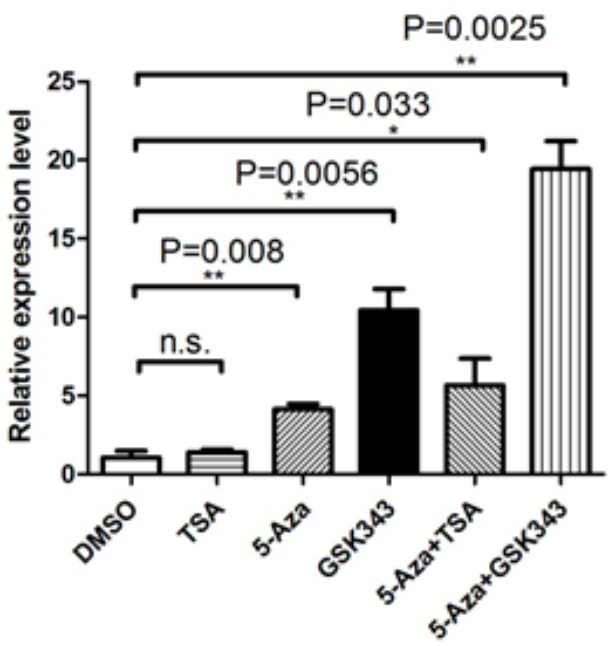

C

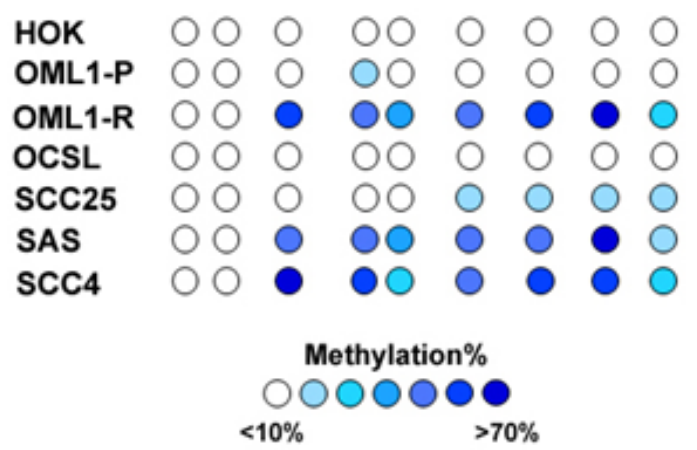

oral cancer has not been fully explored.

In the present study, we used a microarray-based strategy to identify genes differentially methylated in an in vitro model of acquired oral cancer radioresistance. One particularly interesting microarray target, FHIT (fragile histidine triad), was found epigenetically silenced in radioresistant cells. Moreover, restoring expression of epigenetically repressed FHIT resensitized radioresistant oral cancer cells to ionizing radiation. Remarkably, epigenetic interventions using DNMT inhibitors significantly enhanced the radiosensitivity of resistant oral cancer cells, in vivo. Our results together with previous observations [30-31] suggest that concomitant treatment of DNA-demethylating agents and radiotherapy is a new treatment direction for this aggressive malignancy.

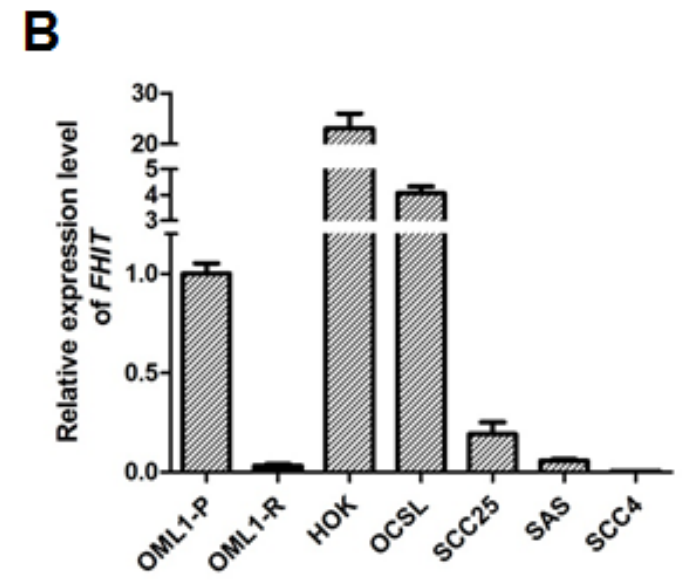

Figure 4: FHIT is epigenetically silenced in oral cancer cells. (A) Relative expression of FHIT in OML1-R cells after epigenetic interventions. OML1-R cells were treated with various drugs as indicated. The expression level of FHIT was then determined by qRT-PCR. The highest reexpression of FHIT was observed in co-treatment with 5-Aza and EZH2 inhibitor, GSK343. (B) Relative expression of FHIT in HOK (human oral keratinocyte), OML1 cells and different oral cancer cell lines (OCSL, SCC25, SAS, SCC4) was determined by qRTPCR, using the expression level of FHIT in OML1-P cells as a reference of 1.0. The highest FHIT expression levels were observed in HOK cells. FHIT promoter methylation levels in these cells were determined by bisulphite sequencing, as shown in (C). The percent methylation of each CpG site is indicated by the intensity of blue. Data in the histogram are expressed as means $\pm \operatorname{SD}(n=3)$. 
A

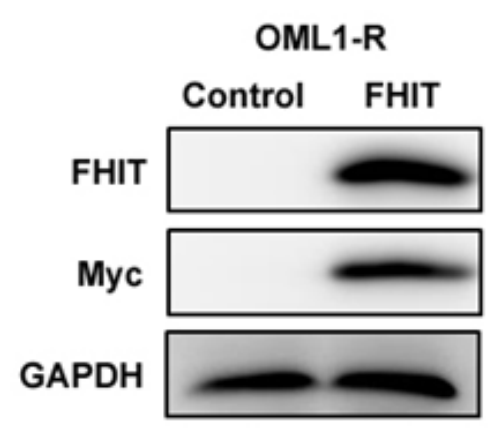

C

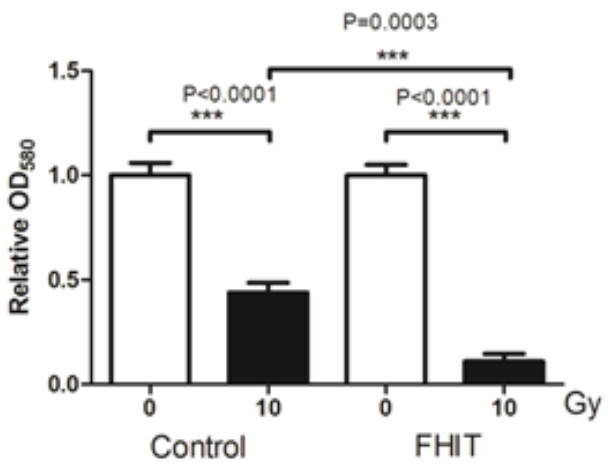

$\mathbf{E}$

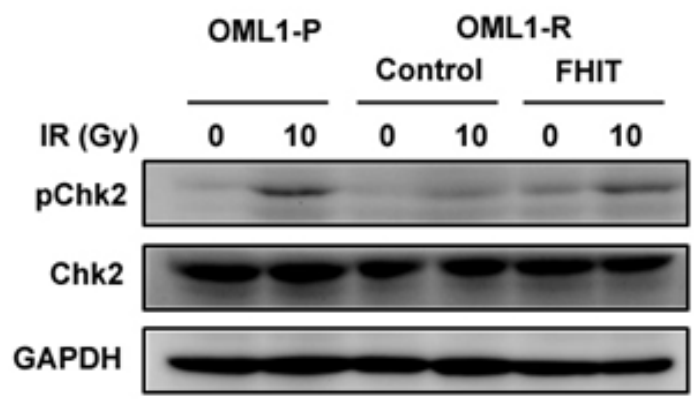

B

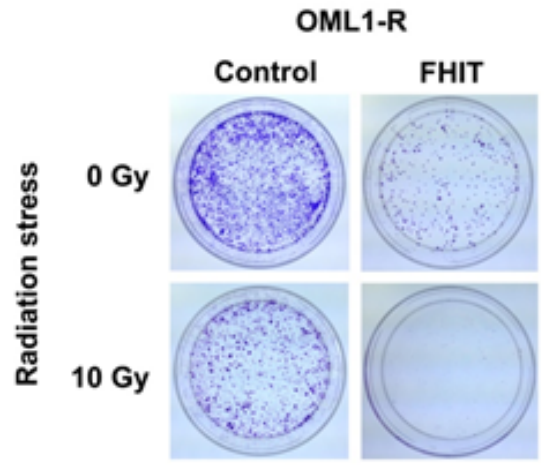

D

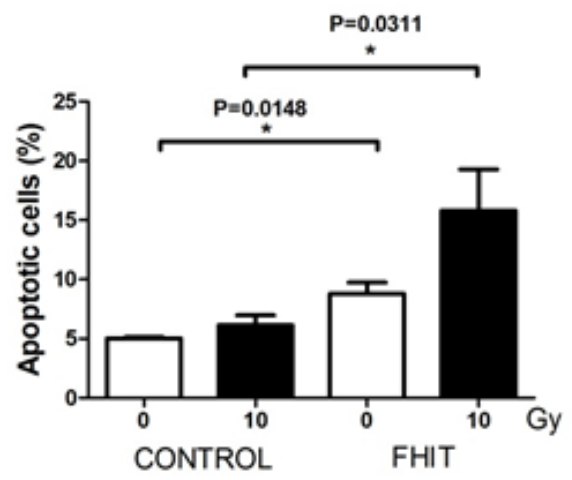

$\mathbf{F}$

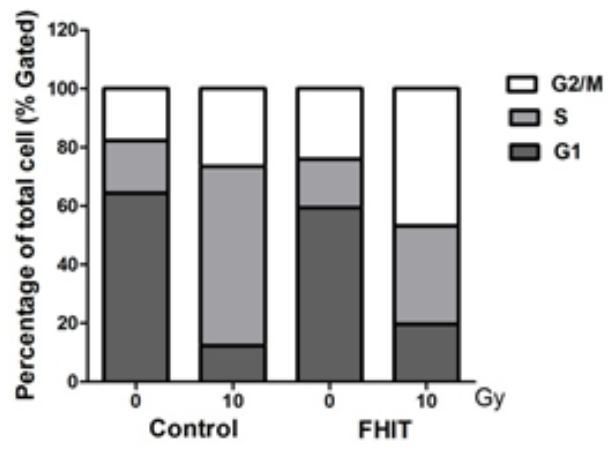

Figure 5: Overexpression of FHIT restores radiosensitivity to OML1-R cells. (A) OML1-R cells overexpressing an FHIT cDNA Myc-Tag plasmid. Protein levels of FHIT, Myc and GAPDH (loading control) in OML1-R cells overexpressing empty vector (control) or FHIT expression vector (FHIT) were analyzed by Western blot. Strong FHIT overexpression was observed in FHIT-overexpressing cells. (B) Radiation stress test in FHIT-overexpressing OML1-R cells. Control or FHIT-overexpressing OML1-R cells were irradiated with a single 10-Gy irradiation in a 10cm dish. FHIT-overexpressing OML1-R cells showed fewer colony numbers than those of control OML1-R cells. The cells were stained with $0.4 \%$ crystal violet and the amount of dye measured by a spectrophotometer as shown in (C). (D) Effect of FHIT on radiation-induced apoptosis in OML1-R cells. Control or FHIT-overexpressing cells were irradiated with a single 10-Gy irradiation shot. Cells were treated with Annexin V-FITC and propidium iodide (PI). The percentage of apoptotic cells were determined by flow cytometry. Representative flow cytometry results can be found in Figure S3. Overexpression of FHIT enhanced radiation-induced apoptosis in OML1-R cells. (E) Protein levels of Chk2, phosphorylated Chk2 (pChk2), and GAPDH (loading control) in OML1-P and FHIT-overexpressing OML1-R cells. Overexpression of FHIT restored phosphorylation of Chk2 in OML1-R cells. (F) Cells were treated with PI and the percentage of cells at different phase of cell cycle was determined by flow cytometry. Data in histograms are expressed as means $\pm \mathrm{SD}(\mathrm{n}=3)$. 
A

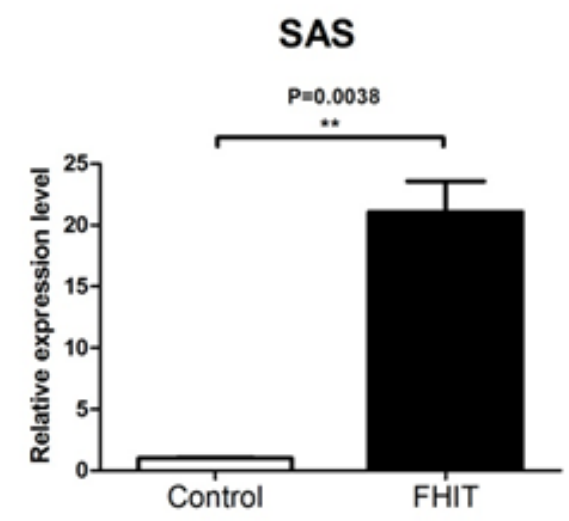

C

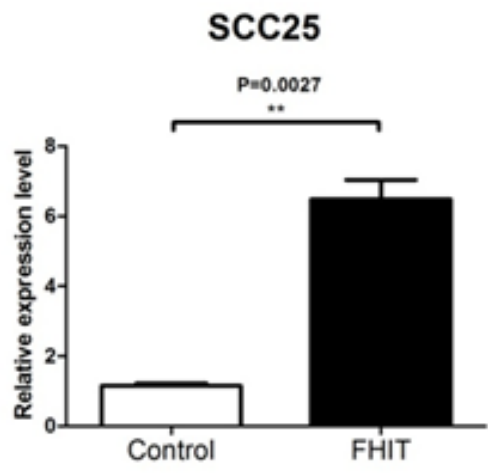

$\mathbf{E}$

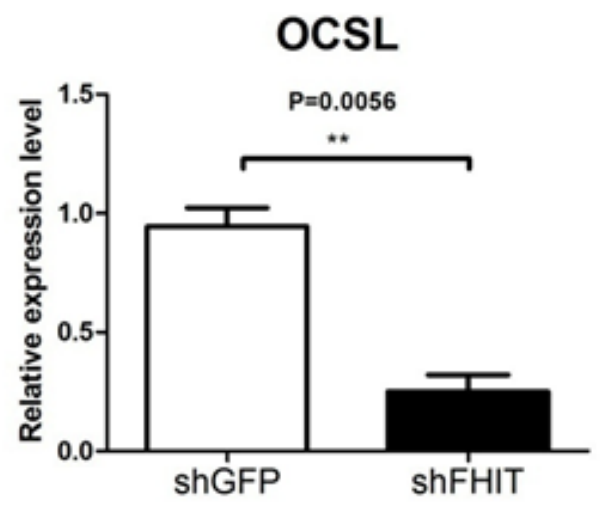

B

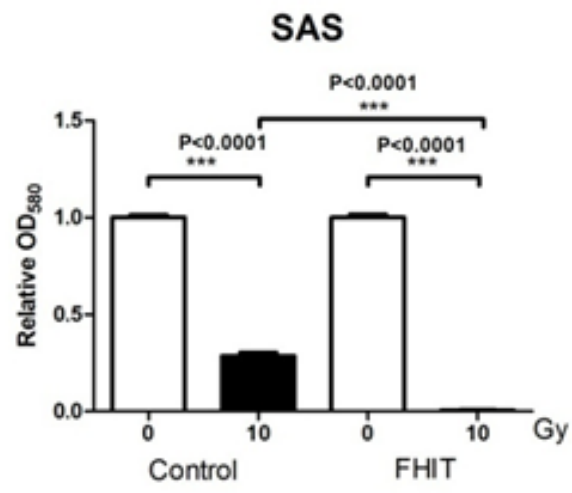

D

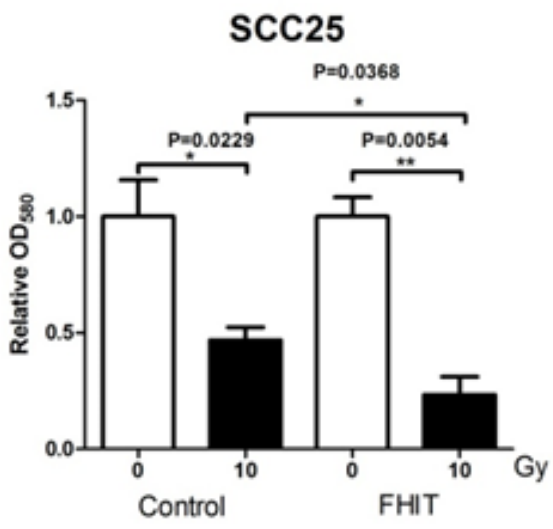

$\mathbf{F}$
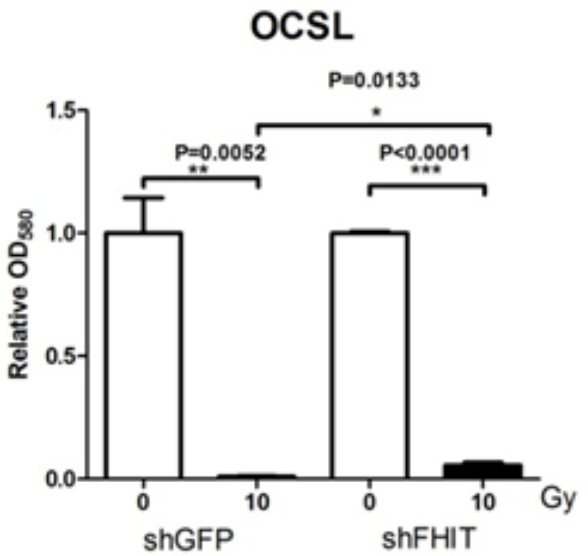

Figure 6: Expression of $\boldsymbol{F H I T}$ determines radiosensitivity in oral cancer cells. FHIT was overexpressed in SAS (A, B) and SCC25 (C, D) oral cancer cells, which both showed low FHIT expression. The relative expression level of FHIT after transfection was determined by qRT-PCR (A, C). Radiosensitivity of the control and FHIT-overexpressing cells was determined by 10-Gy radiation stress test (B, D), as previously mentioned. Overexpression of FHIT significantly enhanced the radiosensitivity of both SAS and SCC25 cells. (E) OCSL oral cancer cells were infected with shRNA against FHIT, resulting in a significant reduction of FHIT expression, as determined by qRT-PCR. (F) Radiation stress test demonstrated a slight reduction of radiosensitivity in FHIT-knockdown OSCL cells. Data in histograms are expressed as means $\pm \operatorname{SD}(n=3)$. 
A

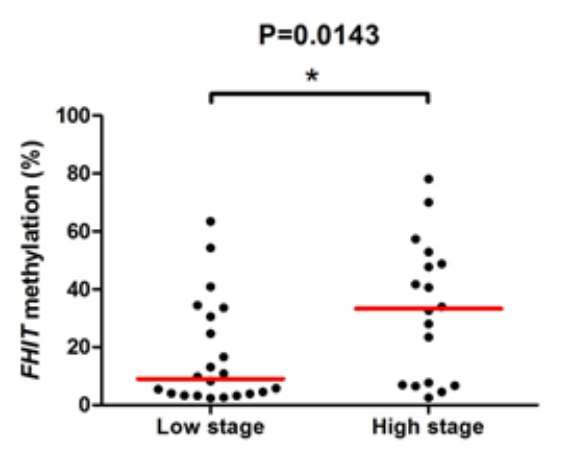

C

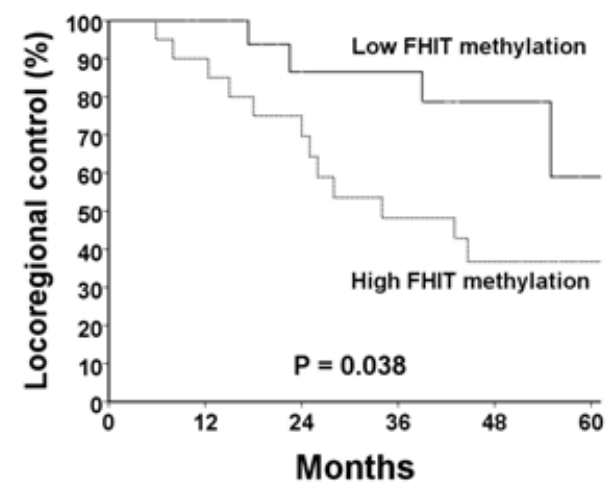

$\mathbf{E}$

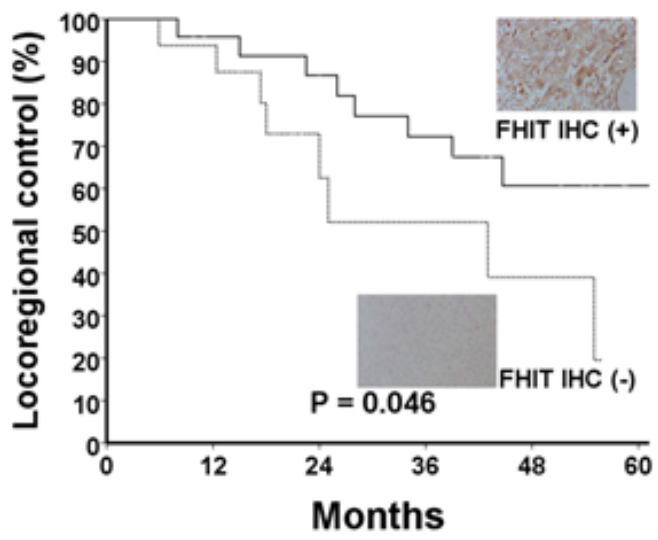

B

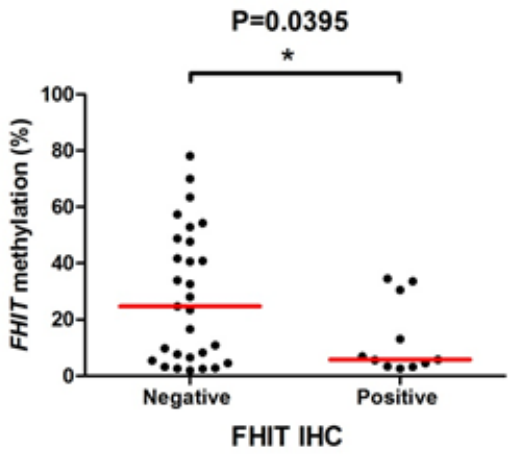

D

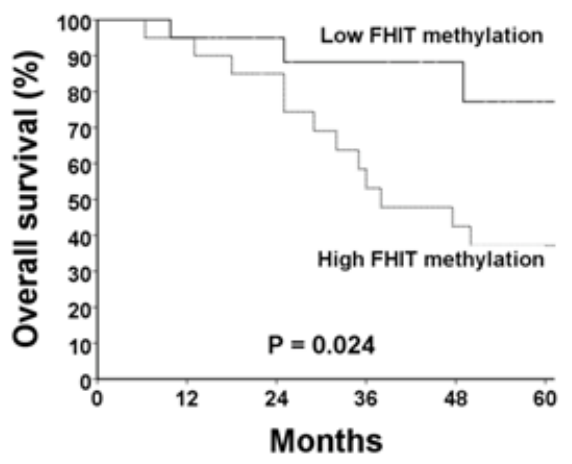

Figure 7: Epigenetic silencing of $\boldsymbol{F H I T}$ associates with poor prognosis in oral cancer patients. (A) FHIT promoter methylation levels in 40 oral cancer patient samples were determined by bisulphite pyrosequencing. Values in dot plots represent average percent methylation of the $9 \mathrm{CpG}$ sites in the FHIT promoter from each sample. High-staged patients (IV A/B) demonstrated significantly higher methylation levels of FHIT than low-staged patients (non-IVA/B). Horizontal lines represent a median level. (B) Association between expression of FHIT and promoter methylation of FHIT in oral cancer patient samples. Patients with negative IHC of FHIT have significantly higher promoter methylation of FHIT than that of patients with positive IHC of FHIT. Kaplan-Meier analysis for locoregional control (C) and overall survival (D) in oral cancer patients. Patients with higher FHIT methylation demonstrated lower locoregional control rates $(P=0.038)$ and shorter overall survival $(P=0.024)$ than patients with lower FHIT methylation. (E) Kaplan Meier analysis showing that oral cancer patients with lower FHIT expression exhibited lower locoregional control $(P=0.046)$ rate than that of patients with higher FHIT expression, as determined by immunohistochemistry. The representative images of positive (upper insert) and negative (lower insert) IHC stain of FHIT are shown (400X). The corresponding high resolution images can be found in Fig. S5. 
FHIT has been reported to be involved in several tumor-suppressive processes, such as enhancing apoptosis [32] and inhibiting tumor growth [33]. On the other hand, reduced FHIT expression has been correlated with increased genome instability [34], decreased DNA damage-induced cell killing [35], and solid tumor progression [36]. However, the role of FHIT in the radioresistance of human cancers is less explored. Herein, we observed a role of FHIT in initiating radioresistance in irradiated oral cancer cells. In vivo and human sample studies validated both therapeutic and predictive efficacy, warranting further clinical trials to confirm these clinical roles.

Ionizing radiation has been reported to induce ATM-Chk2-dependent checkpoint signaling followed by a G2/M cell cycle arrest [37-39], believed to drive sublethally damaged cancer cells toward apoptosis [40-42]. As a result, loss of pChk2 may facilitate cancer cells' escape from checkpoint-dependent apoptosis, leading to a high level of radioresistance [43-44]. Restoring FHIT expression has been observed to restore pChk2 activity and then re-radiosensitization of oral cancer cells [45]. Our data confirmed this observation and re-emphasized the role of reduced apoptosis in the development of radioresistance.

Epigenetic silencing of FHIT has been observed in several human cancers [46-49]. In this study, high promoter methylation of FHIT $(>10 \%)$ can be observed in $55 \%(22 / 40)$ of oral cancer patient samples. Recently, Mielcarek-Kuchta et al. demonstrated that, by using

\section{A}

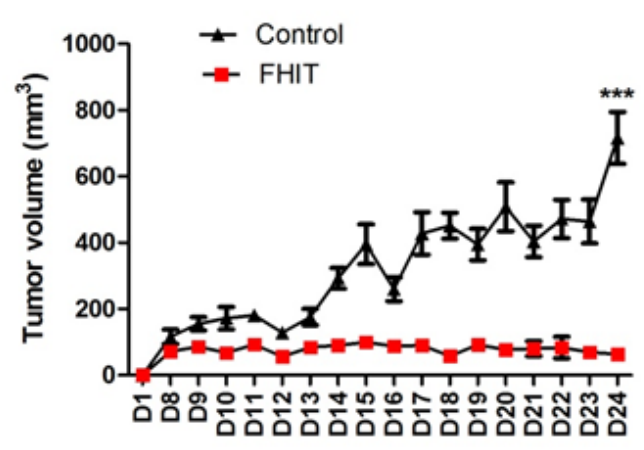

C

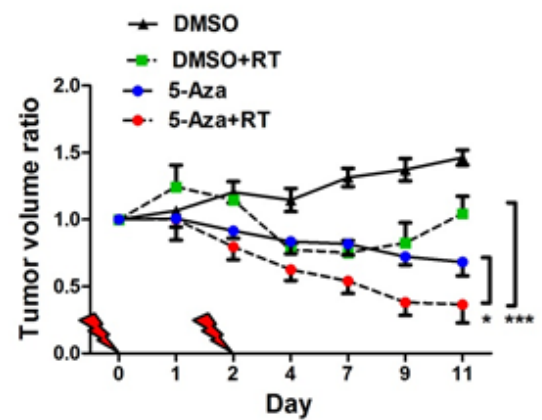

B

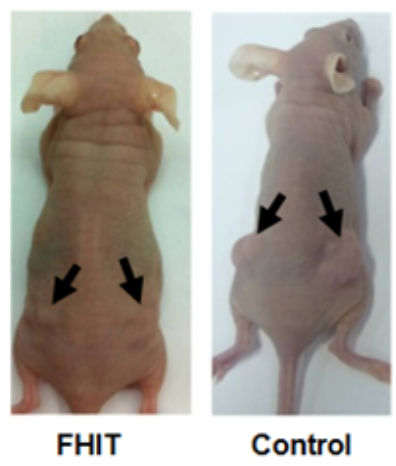

D

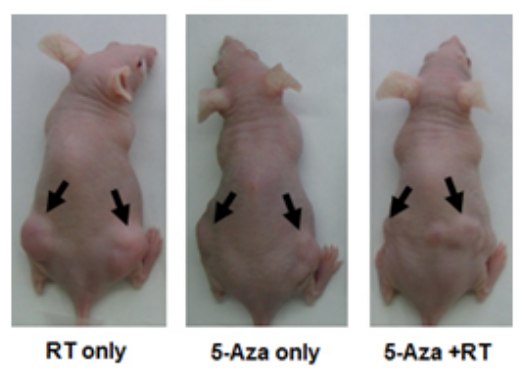

Figure 8: Effect of $\boldsymbol{F H I T}$ expression and epigenetic intervention on tumor growth in an animal model. (A) The effect of FHIT on tumor growth in vivo was also determined by a nude mice model. OML1-R cells stably transfected with FHIT or empty vector (control) were injected subcutaneously into athymic nude mice. Tumor volumes were measured daily. (B) Representative examples of tumors formed in nude mice following injection of OML1-R cells overexpressing FHIT (left panel, arrow) and empty plasmid control (right panel, arrow). Data are expressed as means $\pm \mathrm{SD}(\mathrm{n}=4)$. (C) The effect of irradiation (RT), DNA methylation inhibitor (5-Aza) and combined treatment on radiosensitivity of OML1-R cells in vivo. Radioresistant OML1-R oral cancer cells were injected subcutaneously into athymic nude mice. Tumors were allowed to grow to $>500 \mathrm{~mm}^{3}$ and were then treated with two fractions of 4-Gy irradiation, 5-Aza, or both at the indicated time points (Days 0 and 2). Tumor volumes were measured daily and expressed as tumor volume ratios (tumor volume on the measured day / initial tumor volume on day 0). Statistical significances were observed when comparing tumor volume ratios between 5-Aza + RT and 5-Aza alone (*, $P<0.05$ ) or between 5-Aza + RT and RT alone (***, $P<0.001)$. (D) Representative examples of OML1-R tumors formed in nude mice treated with RT only (left panel, arrow) or 5Aza + RT on day 11 (right panel, arrow). 
methylation specific PCR (MSP), promoter methylation of FHIT was only observed in $1.8 \%$ of 53 cases of oral and oropharyngeal cancer [50]. This discrepancy may be due to a technical difference such that a quantitative bisulphite pyrosequencing was applied in our study. It is also interesting to point out that there is a group of patients with a relatively low methylation of FHIT $(<10 \%)$ but also negative staining of FHIT (Fig 7B). Other mechanisms such as genetic alteration may play a role in the downregulation of FHIT in this group of oral cancer patients [51-53].

Nevertheless, the present study is the first to demonstrate that epigenetic silencing of FHIT can initiate radioresistance in irradiated human oral cancers cells. FHIT is located in the fragile site of chromosome $3 p$ [19], likely a frequent site of DNA damage following irradiation. As a result, repressive histone marks and DNA methylation eventually accumulate within this region, as previously observed [54-55]. Thus, we may conclude that through recruitment of polycomb repressors (e.g., EZH2) and DNMTs, repeated radiation-induced DNA damages results in epigenetic silencing of FHIT, likely initiating post-irradiation radioresistance.

Epigenetic therapy has been recognized as an emerging approach for treating numerous solid cancers [56], particularly in combination with radio- or chemotherapy [29, 57-60]. For examples, decitabine (5Aza) has been reported to enhance radiosensitivity through activating G2/M checkpoint responses, inducing apoptosis in osteosarcoma [61], breast cancer [62], colorectal cancer [63], medulloblastoma [64], and head-and-neck cancers [30-31]. Our results may provide an explanation for the phenomenon that inhibitors of DNMT or EZH2 reverse repressive epigenomes to resensitize radioresistant cancer cells to ionizing radiation.

A more systematic assessment of radiation enhancement by epigenetic interventions has been conducted in head-and-neck cancer cells [31]. However, the role of promoter hypermethylation of FHIT may be underestimated. Based on our data, promoter hypermethylation of FHIT demonstrated dual roles not only in predicting clinical outcomes, but also implicating a treatment target. Thus, further clinical trials to investigate a combined effect of radiotherapy and epigenetic interventions are justified, especially in targeting restoration of FHIT [65].

Unexpected close surgical margin after a radical surgery is frequently encountered in resected oral cancer patients [66-67]. In addition to surgeon effects, unexpected close surgical margins have been recognized partially as an aggressive cancer behavior [68-69]. That is, bioaggressive tumors harboring highly migratory cancer cells demonstrate a higher incidence of unexpected close surgical margins than that of bio-indolent tumors [16]. Clinical data supported this biological reasoning. Patients with close surgical margins demonstrate a higher risk of cancer recurrence and poorer survival than patients with free surgical margin [67, 70-72]. However, close margin alone does not self-sufficiently guide post-operative adjuvants [1, 66, 73-74], this clinical discrepancy reveals a possibly mixed population in these patients. Therefore, exploring a predictive biomarker is valuable for further patient stratification. We have previously confirmed this point of view by identifying promoter hypermethylation of $D A P K$ as a predictive factor for locoregional control [16], and here, we further explored another potential prognostic marker, i,e., promoter hypermethylation of FHIT, as a useful predictor of both locoregional control and overall survival, in irradiated oral cancer patients.

In conclusion, we have identified FHIT as epigenetically silenced by DNA methylation and histone modification in radioresistant oral cancer cells. Epigenetically or ectopically restoring FHIT suppresses tumor growth and enhances radiosensitivity in oral cancer cells. In conjunction with pathological factors, FHIT promoter hypermethylation demonstrates a promising role in predicting clinical outcomes, stratifying high-risk patients, and implicating new potential treatment targets. The radiosensitizing effect of DNMT and/or EZH2 inhibitors warrants further investigation in randomized clinical trials.

\section{MATERIALS AND METHODS}

\section{Ethical considerations}

All experiments involving human samples were conducted in accordance with the Helsinki Declaration of 1975 , as revised in 2000 . This study was also approved by the Institution Review Board (IRB) of the Buddhist Dalin Tzu Chi Hospital, Chia-Yi, Taiwan (approval number: B09804009). All animal experiments were approved by the Animal Experimentation Ethics Committee of the National Chung Cheng University, Taiwan.

\section{Patient samples}

Between Aug 2004 and Dec 2008, we retrospectively selected 40 match-paired oral cancer patient samples based on the distance of surgical margin (Table 1 and Supplementary Fig. S1). Pathological features were prospectively defined at the time of radical surgery by using a checklist, and all of pathological reports were confirmed by two independent pathologists according to the requirement of Taiwan Medical Accreditation on Cancer Center [16]. A cancer case manager and a radiation oncologist independently reviewed all patient records and data discrepancies were resolved by consensus. Locoregional control and overall survival were defined as study end points, as previously described [67, 75]. 
Cancer staging was defined according to the American Joint Committee on Cancer, the $6^{\text {th }}$ edition [76]. For DNA extraction, paraffin-embedded tissue blocks were re-sectioned according to our IRB protocol. Tumorburden areas that contained $>70 \%$ cancer cells were microdissected under microscopy.

\section{Clinical treatment modality}

Radical surgery with a curative intent was conducted in all 40 patients. In primary operation, 19 patients had underwent bone resection, either partial mandibulectomy $(n=16)$ or maxillectomy $(n=3)$. In neck management, supra-omohyoid $(n=25)$ or modified radical neck dissection $(n=15)$ was conducted. All 40 patients were treated with post-operative RT with $(n=21)$ or without $(\mathrm{n}=19)$ cisplatin-based chemotherapy, as previously reported $[67,75]$.

\section{Cell culture and epigenetic treatment}

Oral cancer cell lines OML1, OCSL, SAS (obtained from Dr. Yong-Kie Wong, Department of Dentistry, Taichung Veterans General Hospital, Taichung, Taiwan) were propagated with RPMI Medium 1640 (Gibco, Grand Island, NY) containing 10\% fetal bovine serum (FBS) (Invitrogen, Carlsbad, CA) and 50 units/ml of penicillin/ streptomycin (Invitrogen). The SCC4 and SCC25 cell lines were cultured in a 1:1 mixture of DMEM/F12 (Gibco) supplemented with 10\% fetal bovine serum (FBS, Invitrogen) and 50 units $/ \mathrm{ml}$ of penicillin/streptomycin (Invitrogen). Primary human oral keratinocytes (HOK, ScienCell, Carlsbad, CA) which were isolated from human oral mucosa were cultured in oral keratinocyte medium (OKM, ScienCell). For epigenetic treatment, $2 \times 10^{5}$ cells were seeded onto a $90-\mathrm{mm}$ plate and treated with $0.5 \mu \mathrm{M}$ of 5'-aza-2'-deoxycytidine (5-Aza; Sigma, St. Louis, MO) for 72 hours; $0.5 \mu \mathrm{M}$ Trichostatin A (TSA, Sigma) for 12 hours; or $10 \mu \mathrm{M}$ of EZH2 inhibitor, GSK343 (Cayman, Ann Arbor, MI) for 72 hours. For combination treatment, cells were either treated with 72 hours of 5-Aza followed by 12 hours of TSA or 72 hours of 5-Aza followed by 72 hours of GSK343. Medium was changed and new drug was added every 24 hours.

\section{Establishment of a radioresistant subline by using fractionated irradiations}

For studying the role of epigenetics in oral cancer radioresistance, we established a radioresistant subline of the oral cancer cell line OML1, using hypo-fractionated irradiations (see schema in Fig. 1A). Briefly, one day before irradiation, 1 × $10^{6}$ of the parental ("OML1-P") cells were seeded into $10-\mathrm{cm}$ cell culture plates. A fraction of 5-Gy irradiation was then delivered by a 6-MV linear accelerator (Elekta, Sweden). For achieving equivalent dose distributions, two $1.5-\mathrm{cm}$ biomaterial-equivalent boluses were applied on both up- and down-side of the culture plate (i.e., arranged like a sandwich). After irradiation, cells were allowed to recover for 5-7 days. These procedures were then repeated for 10 sessions, up to a total dose of $50 \mathrm{~Gy}$, to obtain the radioresistant cell subline OML1-R.

\section{Microarray-based methylation analysis}

Bisulphite-modified DNA was subjected to methylation analysis using an Illumina Infinium Human Methylation27 microarray (Illumina, San Diego, CA). Duplicate experiments were then performed to determine methylation $\beta$-values of specific probes, defined as the ratio of the methylated signal intensity to the sum of methylated and unmethylated signal of a probe. A $\beta$-value of 0 represented un-methylation while 1.0 represented full methylation. For selection of differentially methylated probes, the following criteria were applied: 1) probes were present in "CpG islands"; 2) probes having a mean $\beta$-value of $<0.5$ (for hypermethylated probes) or $>0.5$ (for hypomethylated probes) in the control groups (OML1-P cells, as compared to the radioresistant daughter cells); and 3 ) when comparing mean $\beta$-values between experimental groups, probes with both $P<0.05$ and differential changes of $\beta$-value $\geq 0.2$ were obtained.

\section{In vivo tumorigenicity assay}

Four 3-week-old athymic nude mice (BALB/cAnN. Cg-Foxn1nu/CrlNarl) were obtained from National Laboratory Animal Center, Taiwan. All mice were kept under specific pathogen-free conditions using laminar airflow racks, with free access to sterilized food and autoclaved water. All experiments were performed under license from the Animal Experimentation Ethics Committee of the National Chung Cheng University. $1 \mathrm{x}$ $10^{6}$ OML1-R cells stably transfected with empty vector (control) or pcDNA3.1/FHIT were re-suspended in $0.1 \mathrm{ml}$ 1:1 PBS/ Matrigel (BD Bioscience, San Jose, CA) mixture. The cell suspension was then injected subcutaneously into the flank of each mouse (day 0). Tumor length (L) and width $(\mathrm{W})$ were measured daily with calipers, and tumor volume calculated using the formula $\left(\mathrm{Lx} \mathrm{W}^{2} / 2\right)$. At the end of each experiment, all mice were sacrificed. To test the radiosensitizing effect of 5-Aza, 1 x $10^{6}$ OML1-R cells were injected subcutaneously into the flank of each mouse. When the tumor volume exceeded $500 \mathrm{~mm}^{3}$, two fractions of 4-Gy irradiation with 5-Aza (at a dose of $0.5 \mathrm{mg} / \mathrm{kg}$ dissolved in $0.01 \mathrm{M}$ DMSO) or vehicle only (DMSO) were delivered IP, as shown in Fig. 6C. Tumor volume was monitored and presented as the tumor volume growth 
ratios (final volume / initial volume).

\section{Statistical analysis and definitions}

SPSS (version 12.0; SPSS Inc., Chicago, IL, USA) was used for statistical analyses, as follows. KaplanMeier analysis was used to estimate survival and cancer control rates; the log-rank test was applied to assess curve differences between groups; and Cox proportional hazard regression was used to perform univariate and multivariate analyses for time-to-event endpoints. All time-to-event analyses calculated the time interval from the day of pathological diagnosis to the day of corresponding end events, as previously described [67, 75]. A DNA methylation level at $10 \%$, which is the average methylation level in OML1-P cells (Fig. 2C), was used as a cut-off. Independent variables that achieved a statistical significance $(\mathrm{P}<0.05)$ or a statistical trend $(P<0.1$ but $\geq 0.05)$ in univariate analysis were used in multivariate analysis. Comparison of grouped quantitative data was conducted by using student $\mathrm{t}$ test. For demarcating the effective size, 95\% confidence (95\% CI) intervals were provided in conjunction with point-estimated hazard ratios (HRs), in addition to a conventional $P$ value. All tests were two-tailed and considered to be statistically significant when $P<0.05$.

Additional Methods can be found in supplementary information.

\section{CONFLICT OF INTEREST}

Nothing to declare.

\section{ACKNOWLEDGNENTS}

The present study was supported by research grants from: 1). Buddhist Dalin Tzu Chi Hospital (DTCRD99-I-19, DTCRD99(2)-I-15, DTCRD100-I-10, DTCRD101-E-18, DTCRD101(2)-I-14, DTCRD101(2)-I-16, DTCRD102-E-14, DTCRD102(2)-I-12); 2). Interdisciplinary Science grant, National Chung Cheng University (NCCU 103-03); and, 3). Ministry of Science and Technology, Taiwan, ROC (NSC101-2320-B-194-003; NSC102-2320-B-194-006 ; MOST103-2320-B-194-002).

\section{Role of the Funding Source}

All funding sources provided study budgets only.

\section{REFERENCES}

1. NCCN.org. (2014). NCCN Clinical Practice Guidelines in Oncology: Head and Neck Cancer. NCCN Guidelines ${ }^{\mathrm{TM}}$ ).
2. Diez-Perez R, Campo-Trapero J, Cano-Sanchez J, LopezDuran M, Gonzalez-Moles MA, Bascones-Ilundain J and Bascones-Martinez A. Methylation in oral cancer and precancerous lesions (Review). Oncol Rep. 2011.

3. Kordi-Tamandani DM, Moazeni-Roodi AK, Rigi-Ladiz MA, Hashemi M, Birjandian E and Torkamanzehi A. Promoter hypermethylation and expression profile of MGMT and CDH1 genes in oral cavity cancer. Arch Oral Biol. 2010; 55(10):809-814.

4. Taioli E, Ragin C, Wang XH, Chen J, Langevin SM, Brown AR, Gollin SM, Garte S and Sobol RW. Recurrence in oral and pharyngeal cancer is associated with quantitative MGMT promoter methylation. BMC Cancer. 2009; 9:354.

5. Esteller M. Epigenetics in cancer. N Engl J Med. 2008; 358(11):1148-1159.

6. Herman JG and Baylin SB. Gene silencing in cancer in association with promoter hypermethylation. N Engl J Med. 2003; 349(21):2042-2054.

7. Rhee I, Bachman KE, Park BH, Jair KW, Yen RW, Schuebel KE, Cui H, Feinberg AP, Lengauer C, Kinzler KW, Baylin SB and Vogelstein B. DNMT1 and DNMT3b cooperate to silence genes in human cancer cells. Nature. 2002; 416(6880):552-556.

8. Cao R, Wang L, Wang H, Xia L, Erdjument-Bromage H, Tempst P, Jones RS and Zhang Y. Role of histone H3 lysine 27 methylation in Polycomb-group silencing. Science. 2002; 298(5595):1039-1043.

9. Czermin B, Melfi R, McCabe D, Seitz V, Imhof A and Pirrotta V. Drosophila enhancer of Zeste/ESC complexes have a histone $\mathrm{H} 3$ methyltransferase activity that marks chromosomal Polycomb sites. Cell. 2002; 111(2):185-196.

10. Muller J, Hart CM, Francis NJ, Vargas ML, Sengupta A, Wild B, Miller EL, O'Connor MB, Kingston RE and Simon JA. Histone methyltransferase activity of a Drosophila Polycomb group repressor complex. Cell. 2002; 111(2):197208.

11. Vire E, Brenner C, Deplus R, Blanchon L, Fraga M, Didelot C, Morey L, Van Eynde A, Bernard D, Vanderwinden JM, Bollen M, Esteller M, Di Croce L, de Launoit Y and Fuks F. The Polycomb group protein EZH2 directly controls DNA methylation. Nature. 2006; 439(7078):871-874.

12. Chan MW, Chan LW, Tang NL, Tong JH, Lo KW, Lee TL, Cheung HY, Wong WS, Chan PS, Lai FM and To KF. Hypermethylation of multiple genes in tumor tissues and voided urine in urinary bladder cancer patients. Clin Cancer Res. 2002; 8(2):464-470.

13. Chan MW, Wei SH, Wen P, Wang Z, Matei DE, Liu JC, Liyanarachchi S, Brown R, Nephew KP, Yan PS and Huang TH. Hypermethylation of $18 \mathrm{~S}$ and $28 \mathrm{~S}$ ribosomal DNAs predicts progression-free survival in patients with ovarian cancer. Clin Cancer Res. 2005; 11(20):7376-7383.

14. Chen PC, Tsai MH, Yip S, Jou YC, Ng CF, Chen Y, Wang $\mathrm{X}$, Huang W, Tung CL, Chen GC, Huang MM, Tong JH, Song EJ, Chang DC, Hsu CD, To KF, et al. Distinct DNA 
methylation epigenotypes in bladder cancer from different Chinese sub-populations and its implication in cancer detection using voided urine. BMC Med Genomics. 2011; $4: 45$.

15. Esteller M, Corn PG, Baylin SB and Herman JG. A gene hypermethylation profile of human cancer. Cancer Res. 2001; 61(8):3225-3229.

16. Lin HY, Huang TT, Lee MS, Hung SK, Lin RI, Tseng CE, Chang SM, Chiou WY, Hsu FC, Hsu WL, Liu DW, Su YC, Li SC and Chan MW. Unexpected close surgical margin in resected buccal cancer: Very close margin and DAPK promoter hypermethylation predict poor clinical outcomes. Oral Oncol. 2013; 49(4):336-344.

17. Huang da W, Sherman BT and Lempicki RA. Bioinformatics enrichment tools: paths toward the comprehensive functional analysis of large gene lists. Nucleic Acids Res. 2009; 37(1):1-13.

18. Antwih DA, Gabbara KM, Lancaster WD, Ruden DM and Zielske SP. Radiation-induced epigenetic DNA methylation modification of radiation-response pathways. Epigenetics. 2013; 8(8):839-848.

19. Ohta M, Inoue H, Cotticelli MG, Kastury K, Baffa R, Palazzo J, Siprashvili Z, Mori M, McCue P, Druck T, Croce $\mathrm{CM}$ and Huebner K. The FHIT gene, spanning the chromosome 3 p14.2 fragile site and renal carcinomaassociated $\mathrm{t}(3 ; 8)$ breakpoint, is abnormal in digestive tract cancers. Cell. 1996; 84(4):587-597.

20. Sparmann A and van Lohuizen M. Polycomb silencers control cell fate, development and cancer. Nat Rev Cancer. 2006; 6(11):846-856.

21. Schlesinger Y, Straussman R, Keshet I, Farkash S, Hecht M, Zimmerman J, Eden E, Yakhini Z, Ben-Shushan E, Reubinoff BE, Bergman Y, Simon I and Cedar H. Polycomb-mediated methylation on Lys27 of histone H3 pre-marks genes for de novo methylation in cancer. Nat Genet. 2007; 39(2):232-236.

22. Ohm JE, McGarvey KM, Yu X, Cheng L, Schuebel KE, Cope L, Mohammad HP, Chen W, Daniel VC, Yu W, Berman DM, Jenuwein T, Pruitt K, Sharkis SJ, Watkins $\mathrm{DN}$, Herman JG, et al. A stem cell-like chromatin pattern may predispose tumor suppressor genes to DNA hypermethylation and heritable silencing. Nat Genet. 2007; 39(2):237-242.

23. Statham AL, Robinson MD, Song JZ, Coolen MW, Stirzaker C and Clark SJ. Bisulfite sequencing of chromatin immunoprecipitated DNA (BisChIP-seq) directly informs methylation status of histone-modified DNA. Genome Res. 2012; 22(6):1120-1127.

24. Kondo Y, Shen L, Cheng AS, Ahmed S, Boumber Y, Charo C, Yamochi T, Urano T, Furukawa K, Kwabi-Addo B, Gold DL, Sekido Y, Huang TH and Issa JP. Gene silencing in cancer by histone $\mathrm{H} 3$ lysine 27 trimethylation independent of promoter DNA methylation. Nat Genet. 2008; 40(6):741750.
25. Brinkman AB, Gu H, Bartels SJ, Zhang Y, Matarese F, Simmer F, Marks H, Bock C, Gnirke A, Meissner A and Stunnenberg HG. Sequential ChIP-bisulfite sequencing enables direct genome-scale investigation of chromatin and DNA methylation cross-talk. Genome Res. 2012; 22(6):1128-1138.

26. Verma SK, Tian X, LaFrance LV, Duquenne C, Suarez DP, Newlander KA, Romeril SP, Burgess JL, Grant SW, Brackley JA, Graves AP, Scherzer DA, Shu A, Thompson C, Ott HM, Aller GS, et al. Identification of Potent, Selective, Cell-Active Inhibitors of the Histone Lysine Methyltransferase EZH2. ACS Med Chem Lett. 2012; 3(12):1091-1096.

27. Popovtzer A, Gluck I, Chepeha DB, Teknos TN, Moyer JS, Prince ME, Bradford CR and Eisbruch A. The pattern of failure after reirradiation of recurrent squamous cell head and neck cancer: implications for defining the targets. Int $\mathbf{J}$ Radiat Oncol Biol Phys. 2009; 74(5):1342-1347.

28. Lee JC, Lee WH, Min YJ, Cha HJ, Han MW, Chang HW, Kim SA, Choi SH, Kim SW and Kim SY. Development of TRAIL resistance by radiation-induced hypermethylation of DR4 CpG island in recurrent laryngeal squamous cell carcinoma. Int J Radiat Oncol Biol Phys. 2014; 88(5):12031211.

29. Kim EH, Park AK, Dong SM, Ahn JH and Park WY. Global analysis of $\mathrm{CpG}$ methylation reveals epigenetic control of the radiosensitivity in lung cancer cell lines. Oncogene. 2010.

30. Brieger J, Mann SA, Pongsapich W, Koutsimpelas D, Fruth $\mathrm{K}$ and Mann WJ. Pharmacological genome demethylation increases radiosensitivity of head and neck squamous carcinoma cells. Int J Mol Med. 2012; 29(3):505-509.

31. De Schutter H, Kimpe M, Isebaert S and Nuyts S. A systematic assessment of radiation dose enhancement by 5-Aza-2'-deoxycytidine and histone deacetylase inhibitors in head-and-neck squamous cell carcinoma. Int J Radiat Oncol Biol Phys. 2009; 73(3):904-912.

32. Sevignani C, Calin GA, Cesari R, Sarti M, Ishii H, Yendamuri S, Vecchione A, Trapasso F and Croce CM. Restoration of fragile histidine triad (FHIT) expression induces apoptosis and suppresses tumorigenicity in breast cancer cell lines. Cancer Res. 2003; 63(6):1183-1187.

33. Siprashvili Z, Sozzi G, Barnes LD, McCue P, Robinson AK, Eryomin V, Sard L, Tagliabue E, Greco A, Fusetti L, Schwartz G, Pierotti MA, Croce CM and Huebner K. Replacement of Fhit in cancer cells suppresses tumorigenicity. Proc Natl Acad Sci U S A. 1997; 94(25):13771-13776.

34. Saldivar JC, Miuma S, Bene J, Hosseini SA, Shibata H, Sun J, Wheeler LJ, Mathews CK and Huebner K. Initiation of Genome Instability and Preneoplastic Processes through Loss of Fhit Expression. PLoS Genet. 2012; 8(11):e1003077.

35. Lin YX, Yu F, Gao N, Sheng JP, Qiu JZ and Hu BC. microRNA-143 protects cells from DNA damage-induced 
killing by downregulating FHIT expression. Cancer Biother Radiopharm. 2011; 26(3):365-372.

36. Kapitanovic S, Cacev T, Loncar B, Catela Ivkovic T, Krizanac S and Pavelic K. Reduced FHIT expression is associated with tumor progression in sporadic colon adenocarcinoma. Exp Mol Pathol. 2014; 96(1):92-97.

37. Momcilovic O, Choi S, Varum S, Bakkenist C, Schatten $\mathrm{G}$ and Navara C. Ionizing radiation induces ataxia telangiectasia mutated-dependent checkpoint signaling and $\mathrm{G}(2)$ but not $\mathrm{G}(1)$ cell cycle arrest in pluripotent human embryonic stem cells. Stem Cells. 2009; 27(8):1822-1835.

38. Zhou W, Sun M, Li GH, Wu YZ, Wang Y, Jin F, Zhang YY, Yang L and Wang DL. Activation of the phosphorylation of ATM contributes to radioresistance of glioma stem cells. Oncol Rep. 2013; 30(4):1793-1801.

39. Wang WJ, Wu SP, Liu JB, Shi YS, Huang X, Zhang QB and Yao KT. MYC regulation of CHK1 and CHK2 promotes radioresistance in a stem cell-like population of nasopharyngeal carcinoma cells. Cancer Res. 2013; 73(3):1219-1231.

40. Rainey MD, Black EJ, Zachos G and Gillespie DA. Chk2 is required for optimal mitotic delay in response to irradiationinduced DNA damage incurred in G2 phase. Oncogene. 2008; 27(7):896-906.

41. Gogineni VR, Nalla AK, Gupta R, Dinh DH, Klopfenstein JD and Rao JS. Chk2-mediated G2/M cell cycle arrest maintains radiation resistance in malignant meningioma cells. Cancer Lett. 2011; 313(1):64-75.

42. Chen C, Shimizu S, Tsujimoto Y and Motoyama N. Chk2 regulates transcription-independent $\mathrm{p} 53$-mediated apoptosis in response to DNA damage. Biochem Biophys Res Commun. 2005; 333(2):427-431.

43. Squatrito M, Brennan CW, Helmy K, Huse JT, Petrini $\mathrm{JH}$ and Holland EC. Loss of ATM/Chk2/p53 pathway components accelerates tumor development and contributes to radiation resistance in gliomas. Cancer Cell. 2010; 18(6):619-629.

44. Takai H, Naka K, Okada Y, Watanabe M, Harada N, Saito S, Anderson CW, Appella E, Nakanishi M, Suzuki H, Nagashima K, Sawa H, Ikeda K and Motoyama N. Chk2deficient mice exhibit radioresistance and defective p53mediated transcription. EMBO J. 2002; 21(19):5195-5205.

45. Yutori H, Semba S, Komori T and Yokozaki H. Restoration of fragile histidine triad expression restores Chk2 activity in response to ionizing radiation in oral squamous cell carcinoma cells. Cancer Sci. 2008; 99(3):524-530.

46. Han SY, Iliopoulos D, Druck T, Guler G, Grubbs CJ, Pereira M, Zhang Z, You M, Lubet RA, Fong LY and Huebner K. CpG methylation in the Fhit regulatory region: relation to Fhit expression in murine tumors. Oncogene. 2004; 23(22):3990-3998.

47. Tanaka H, Shimada Y, Harada H, Shinoda M, Hatooka $\mathrm{S}$, Imamura $\mathrm{M}$ and Ishizaki $\mathrm{K}$. Methylation of the 5, $\mathrm{CpG}$ island of the FHIT gene is closely associated with transcriptional inactivation in esophageal squamous cell carcinomas. Cancer Res. 1998; 58(15):3429-3434.

48. Zochbauer-Muller S, Fong KM, Maitra A, Lam S, Geradts J, Ashfaq R, Virmani AK, Milchgrub S, Gazdar AF and Minna JD. 5' CpG island methylation of the FHIT gene is correlated with loss of gene expression in lung and breast cancer. Cancer Res. 2001; 61(9):3581-3585.

49. Chang KW, Kao SY, Tzeng RJ, Liu CJ, Cheng AJ, Yang SC, Wong YK and Lin SC. Multiple molecular alterations of FHIT in betel-associated oral carcinoma. J Pathol. 2002; 196(3):300-306.

50. Mielcarek-Kuchta D, Paluszczak J, Seget M, Kiwerska K, Biczysko W, Szyfter K and Szyfter W. Prognostic factors in oral and oropharyngeal cancer based on ultrastructural analysis and DNA methylation of the tumor and surgical margin. Tumour Biol. 2014; 35(8):7441-7449.

51. Joo YH, Park SW, Jung SH, Lee YS, Nam IC, Cho KJ, Park JO, Chung YJ and Kim MS. Recurrent loss of the FHIT gene and its impact on lymphatic metastasis in early oral squamous cell carcinoma. Acta Otolaryngol. 2013; 133(9):992-999.

52. Ribeiro IP, Marques F, Caramelo F, Ferrao J, Prazeres H, Juliao MJ, Rifi W, Savola S, de Melo JB, Baptista IP and Carreira IM. Genetic imbalances detected by multiplex ligation-dependent probe amplification in a cohort of patients with oral squamous cell carcinoma-the first step towards clinical personalized medicine. Tumour Biol. 2014; 35(5):4687-4695.

53. Tanimoto K, Hayashi S, Tsuchiya E, Tokuchi Y, Kobayashi Y, Yoshiga K, Okui T, Kobayashi M and Ichikawa T. Abnormalities of the FHIT gene in human oral carcinogenesis. Br J Cancer. 2000; 82(4):838-843.

54. O'Hagan HM, Mohammad HP and Baylin SB. Double strand breaks can initiate gene silencing and SIRT1dependent onset of DNA methylation in an exogenous promoter CpG island. PLoS Genet. 2008; 4(8):e1000155.

55. Ayrapetov MK, Gursoy-Yuzugullu $\mathrm{O}, \mathrm{Xu} \mathrm{C}, \mathrm{Xu} \mathrm{Y}$ and Price BD. DNA double-strand breaks promote methylation of histone $\mathrm{H} 3$ on lysine 9 and transient formation of repressive chromatin. Proc Natl Acad Sci U S A. 2014; 111(25):9169-9174.

56. Ahuja N, Easwaran H and Baylin SB. Harnessing the potential of epigenetic therapy to target solid tumors. J Clin Invest. 2014; 124(1):56-63.

57. Kim JG, Park MT, Heo K, Yang KM and Yi JM. Epigenetics meets radiation biology as a new approach in cancer treatment. Int J Mol Sci. 2013; 14(7):15059-15073.

58. Groselj B, Sharma NL, Hamdy FC, Kerr M and Kiltie AE. Histone deacetylase inhibitors as radiosensitisers: effects on DNA damage signalling and repair. Br J Cancer. 2013; 108(4):748-754.

59. Gravina GL, Festuccia C, Marampon F, Popov VM, Pestell RG, Zani BM and Tombolini V. Biological rationale for the use of DNA methyltransferase inhibitors as new strategy 
for modulation of tumor response to chemotherapy and radiation. Mol Cancer. 2010; 9:305.

60. Palanichamy K and Chakravarti A. Combining drugs and radiotherapy: from the bench to the bedside. Curr Opin Neurol. 2009; 22(6):625-632.

61. Li Y, Geng P, Jiang W, Wang Y, Yao J, Lin X, Liu J, Huang L, Su B and Chen H. Enhancement of radiosensitivity by 5 -Aza-CdR through activation of G2/M checkpoint response and apoptosis in osteosarcoma cells. Tumour Biol. 2014; 35(5):4831-4839.

62. Wang L, Zhang Y, Li R, Chen Y, Pan X, Li G, Dai $F$ and Yang J. 5-aza-2'-Deoxycytidine enhances the radiosensitivity of breast cancer cells. Cancer Biother Radiopharm. 2013; 28(1):34-44.

63. Hofstetter B, Niemierko A, Forrer C, Benhattar J, Albertini V, Pruschy M, Bosman FT, Catapano CV and Ciernik IF. Impact of genomic methylation on radiation sensitivity of colorectal carcinoma. Int J Radiat Oncol Biol Phys. 2010; 76(5):1512-1519.

64. Patties I, Jahns J, Hildebrandt G, Kortmann RD and Glasow A. Additive effects of 5-aza-2'-deoxycytidine and irradiation on clonogenic survival of human medulloblastoma cell lines. Strahlenther Onkol. 2009; 185(5):331-338.

65. Maeder ML, Angstman JF, Richardson ME, Linder SJ, Cascio VM, Tsai SQ, Ho QH, Sander JD, Reyon D, Bernstein BE, Costello JF, Wilkinson MF and Joung JK. Targeted DNA demethylation and activation of endogenous genes using programmable TALE-TET1 fusion proteins. Nat Biotechnol. 2013; 31(12):1137-1142.

66. Jan JC, Hsu WH, Liu SA, Wong YK, Poon CK, Jiang RS, Jan JS and Chen IF. Prognostic factors in patients with buccal squamous cell carcinoma: 10-year experience. J Oral Maxillofac Surg. 2011; 69(2):396-404.

67. Chiou WY, Lin HY, Hsu FC, Lee MS, Ho HC, Su YC, Lee $\mathrm{CC}$, Hsieh CH, Wang YC and Hung SK. Buccal mucosa carcinoma: surgical margin less than $3 \mathrm{~mm}$, not $5 \mathrm{~mm}$, predicts locoregional recurrence. Radiat Oncol. 2010; 5:79.

68. Sutton DN, Brown JS, Rogers SN, Vaughan ED and Woolgar JA. The prognostic implications of the surgical margin in oral squamous cell carcinoma. Int $\mathrm{J}$ Oral Maxillofac Surg. 2003; 32(1):30-34.

69. Upile T, Fisher C, Jerjes W, El Maaytah M, Searle A, Archer D, Michaels L, Rhys-Evans P, Hopper C, Howard $\mathrm{D}$ and Wright $\mathrm{A}$. The uncertainty of the surgical margin in the treatment of head and neck cancer. Oral Oncol. 2007; 43(4):321-326.

70. Chen TC, Wang CP, Ko JY, Yang TL and Lou PJ. The impact of pathologic close margin on the survival of patients with early stage oral squamous cell carcinoma. Oral Oncol. 2012; 48(7):623-628.

71. Meier JD, Oliver DA and Varvares MA. Surgical margin determination in head and neck oncology: current clinical practice. The results of an International American Head and Neck Society Member Survey. Head Neck. 2005; 27(11):952-958.

72. Nason RW, Binahmed A, Pathak KA, Abdoh AA and Sandor GK. What is the adequate margin of surgical resection in oral cancer? Oral Surg Oral Med Oral Pathol Oral Radiol Endod. 2009; 107(5):625-629.

73. Bernier J, Cooper JS, Pajak TF, van Glabbeke M, Bourhis J, Forastiere A, Ozsahin EM, Jacobs JR, Jassem J, Ang KK and Lefebvre JL. Defining risk levels in locally advanced head and neck cancers: a comparative analysis of concurrent postoperative radiation plus chemotherapy trials of the EORTC (\#22931) and RTOG (\# 9501). Head Neck. 2005; 27(10):843-850.

74. Brandwein-Gensler M, Teixeira MS, Lewis CM, Lee B, Rolnitzky L, Hille JJ, Genden E, Urken ML and Wang BY. Oral squamous cell carcinoma: histologic risk assessment, but not margin status, is strongly predictive of local disease-free and overall survival. Am J Surg Pathol. 2005; 29(2):167-178.

75. Tsai WT, Lee MS, Hung SK, Chiou WY, Huang TT, Tseng CE, Chang SM, Hsu FC, Su YC and Li SC. A very close margin of $\leq 1 \mathrm{~mm}$ predicts a poor outcome in resected buccal cancer patients with a pathological margin of $\leq 3$ mm. Tzu Chi Medical Journal. 2011.

76. Greene FL. (2006). AJCC cancer staging atlas. (New York, NY: Springer). 